\title{
Donor-Acceptor Interactions in Red-Emitting Thienylbenzene-Branched Dendrimers with Benzothiadiazole Core
}

\author{
K. R. Justin Thomas, ${ }^{[a]}$ Tai-Hsiang Huang, ${ }^{[a]}$ Jiann T. Lin, ${ }^{*[a, ~ b] ~ S h i n-C h i e n ~ P u, ~}{ }^{[c]}$ \\ Yi-Ming Cheng, ${ }^{[\mathrm{cc}]}$ Cheng-Chih Hsieh, ${ }^{[\mathrm{c}]}$ and Chou Pi Tai ${ }^{*[c]}$
}

\begin{abstract}
Synthesis and characterization of dendrimers containing thienylbenzene repeating units, red-emitting benzothiadiazole core, and triarylamine peripheries that bear naphthyl units are reported. The relevant dendrimers of different generations are classified as $\mathbf{G}_{\boldsymbol{n} \mathbf{b}}(n=1-3)$, while the tert-butyl dendrimers $\mathbf{G}_{n \mathbf{a}}$ with the acceptor alone were also synthesized to serve as control chromophores that avoid donoracceptor interactions. The resulting
\end{abstract}

dendrimers are capable of harvesting photon energy through efficient energy transfer among donor-acceptor moieties, so that highly luminescent red fluorophores result. Transient fluorescence studies suggest that the energy transfer and its efficiency are approximately

Keywords: charge transfer $\cdot$ dendrimers $\cdot$ donor-acceptor systems • energy harvesting $\cdot$ luminescence

\section{Introduction}

Dendrimers are attractive as molecular architectures for studying energy harvesting properties ${ }^{[1]}$ and for their ability to encapsulate small band gap chromophores within bulky peripheral masking units. ${ }^{[2]}$ With a view to applications, the recently developed site-isolation strategy has greatly extended their usefulness in the design of functional molecules with multichromophore units. ${ }^{[3]}$ This approach is beneficial for avoiding detrimental interchromophore interactions, particularly for small-band-gap chromophores that are subject to aggregation because of dipole-dipole or $\pi$-stacking inter-

[a] Dr. K. R. J. Thomas, Dr. T.-H. Huang, Prof. Dr. J. T. Lin Institute of Chemistry

Academia Sinica

Taipei 115 (Taiwan)

E-mail: jtlin@chem.sinica.edu.tw

[b] Prof. Dr. J. T. Lin

Department of Chemistry

National Central University

Chungli 320 (Taiwan)

[c] Dr. S.-C. Pu, Dr. Y.-M. Cheng, C.-C. Hsieh, Prof. Dr. C. P. Tai

Department of Chemistry

National Taiwan University

Taipei 106 (Taiwan)

E-mail: chop@ntu.edu.tw actions. These interactions normally result in crystallinity and hence deviations of luminescence properties such as shift in emission color and reduced emission yield. ${ }^{[4]}$ Prototypical examples are the perylenediimides, which are often in a crystalline form that displays less intense emission in both solid and solution phases. It is also possible to suppress intermolecular interactions by doping such chromophores into an amorphous matrix. However, the physically blended systems, obtained by either evaporation or solution casting, may lead to uneven distribution of guests. As a result, localized high concentrations can lead to detrimental quenching effects. Alternatively, an efficient way of controlling molecular interactions is to deposit them at the molecular level, so that the chromophores can be organized precisely within the molecular framework. Dendrimers offer a suitable platform for such endeavors. In sharp contrast to the bulk properties, incorporation of a small-band-gap chromophore into the dendrimer core may enhance the emission features simply due to prohibition of interchromophore interactions and possible energy transfer from peripheral chromophores. On this basis, for typical dendrimers with the emission originating from the core functional group, the fluorescence quantum yield may rapidly increase with increasing generation, in the absence of other side effects such as electron-transfer quenching by the peripheral functional groups (vide infra). Moreover, multifunctional dendrimers may be beneficial for 
charge transport as the dendrimer framework may provide a facile vectorial contribution to the hopping/migration/trapping pathways.

Recently, we and others have demonstrated that peripheral triarylamines can be effectively used to encapsulate small-band-gap cores such as thienylpyrazine, ${ }^{[5]}$ benzothiadiazole ${ }^{[6]}$ and peryleneimide. ${ }^{[7]}$ Here we describe the synthesis and characterization of a new family of dendrimers in which thienylbenzene branches are peripherally decorated with $N$-phenylnaphthylamine units and focally converge at a benzothiadiazole core. In this approach, rigid and conjugated dendrimers were selected because they potentially have enhanced thermal stability and fewer nonradiative deactivation pathways (vide infra). Thienyl ${ }^{[8]}$ and phenylene ${ }^{[9]} \pi$-conjugated dendrimers have been recently synthesized and their photophysical properties were found to be unique when compared to other nonconjugated, flexible dendrimers. However, to the best of our knowledge, dendrimers having thienylbenzene repeating units are rare in the literature. Normally, polythiophenes and thiophene oligomers exhibit diminished quantum efficiency, partly due to the heavyatom effect in combination with oxidative quenching. Replacement of one or more thiophene moieties by a phenyl unit improves the fluorescence properties with a slight compromise in the emission peak wavelength. ${ }^{[10]}$ Accordingly, the title dendrimers, which contain redemitting benzothiadiazole as core, thienylbenzene repeating units, and triarylamine peripheries bearing naphthyl units should establish an efficient energy-transfer framework leading to highly luminescent red fluorophores. We used time-resolved spectroscopic methods to unravel the energymigration pathways in these dendrimers. In light of their high glass transition temperatures $\left(176-201^{\circ} \mathrm{C}\right)$, these new dendrimers may pave a new avenue for applications in electroluminescent devices.

\section{Results and Discussion}

Synthesis and characterization: Our main focus is on two types of thienylbenzene-branch-based dendrimers having surface groups of different naturestert-butyl or $N$-(4-tert-butylphenyl)- $N$-phenylnaphthalen-1- amine-but the same core structure, namely, the long conjugated aromatic segment 4,7-bis(5-phenylthiophen-2yl)benzo $[c][1,2,5]$ thiadiazole. The dendrimers with triarylamine peripheries $\mathbf{G}_{\boldsymbol{n} \mathbf{b}}(n=1-3)$ have donor-acceptor architecture and hence are considered to be functional dendrimers, while the tert-butyl dendrimers $\mathbf{G}_{n \mathbf{a}}(n=1-3)$ with the acceptor alone serve as control chromophores devoid of donor-acceptor interactions. Thus, these dendrimers allow us to unravel the donor-acceptor interactions in a dendritic environment.

One can perceive a feasible energy-transformation pathway in these functional dendrimers: First, the energy absorbed by the periphery may migrate to the core by an efficient energy-transfer pathway, the mechanism of which is most likely of the Förster type, that is, dipole-induced dipole-transition energy transfer. The energy accumulated at the core can then be released either as core (red) emission or deactivated (quenched) by an electron transfer process from the periphery. In the latter case, it is necessary to match the redox potentials between periphery and core. Bearing these concepts in mind, we designed and synthesized dendrimers in which the associated chromophores can
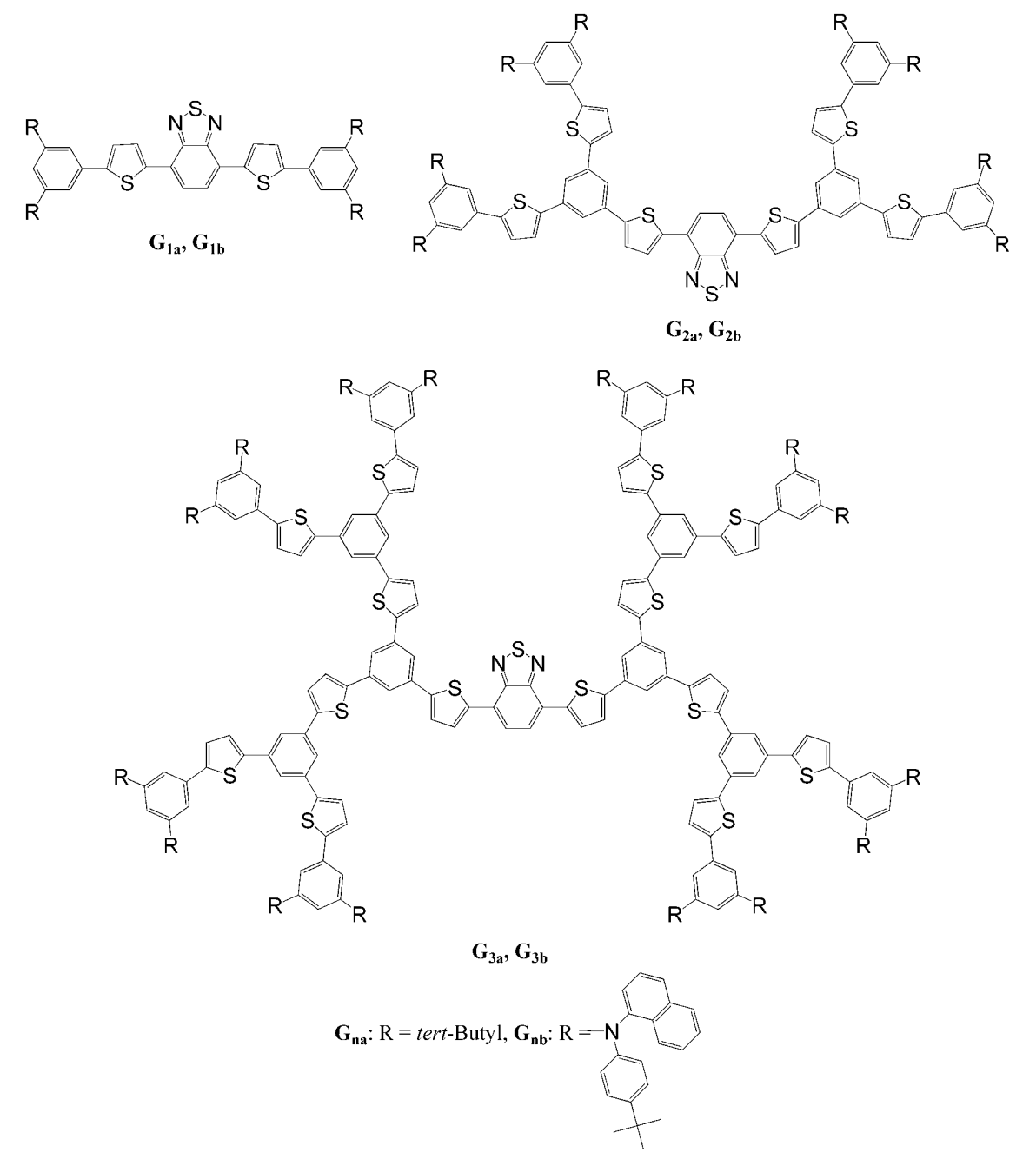
be bifunctional, that is, undergo energy and electron transfer.

Generally, in modular dendrimer synthesis, the core unit and dendrons are prepared separately and finally tethered together to achieve the dendritic configuration. Conversely, in our approach, the core unit can be self-assembled in the final step and the dendron itself generally contains part of the core segment. Schemes 1 and 2 outline the synthetic methodologies for the dendrons, while Scheme 3 shows the synthetic route to the dendrimers. Monodendrons $\mathbf{2} \mathbf{a}$ and $\mathbf{2 b}$

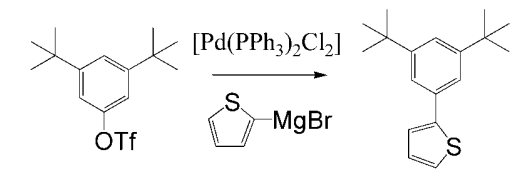

2a

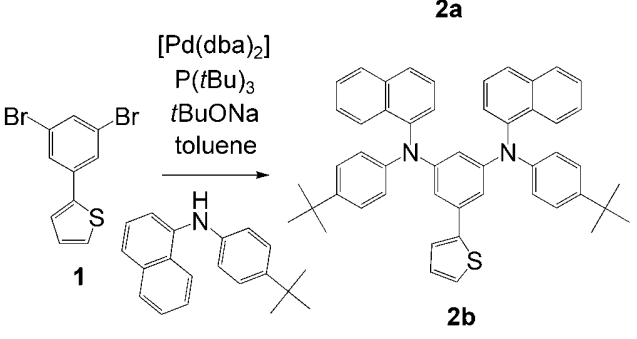

Scheme 1. Synthesis of the first-generation dendrons. dba $=$ trans,trans-dibenzylideneacetone. were obtained by different routes (Scheme 1), elaborated in the following.

The $\mathrm{G}_{1 \mathrm{a}}$ dendron $\mathbf{2 a}$ was synthesized from 3,5-di-tert-butylphenyl trifluoromethanesulfonate by treatment with thiophen-2-ylmagnesium bromide in the presence of [Pd$\left(\mathrm{PPh}_{3}\right)_{2} \mathrm{Cl}_{2}$ ] as catalyst, and $\mathrm{G}_{1 \mathrm{~b}}$ dendron $\mathbf{2 b}$ by $\mathrm{C}-\mathrm{N}$ coupling between $N$-(4-tert-butylphenyl)naphthalen-2-amine and 2-(3,5-dibromophenyl)thiophene (1) catalyzed by [Pd$\left.(\mathrm{dba})_{2}\right] / t \mathrm{Bu}_{3} \mathrm{P}$. Subsequently, by treatment with $n \mathrm{BuLi}$ and $n \mathrm{Bu}_{3} \mathrm{SnCl}$, the thiophenyl-substituted dendrons were converted to stannylene derivatives, which were treated with 2 (3,5-dibromophenyl)thiophene (1) in a $\left[\mathrm{Pd}\left(\mathrm{PPh}_{3}\right)_{2} \mathrm{Cl}_{2}\right]$-catalyzed Stille reaction to give $\mathrm{G}_{2}$ dendrons 3 (Scheme 2). The above two steps were repeated on $\mathrm{G}_{2}$ dendrons to generate $\mathrm{G}_{3}$ dendrons 4. Finally, the dendrimers were obtained in moderate to good yield by twofold Stille coupling between the corresponding stannylene derivatives of the dendrons and 4,7-dibromobenzothiadiazole (Scheme 3). The dendrimers are red or deep red in appearance and soluble in most organic solvents. The structural composition of the new

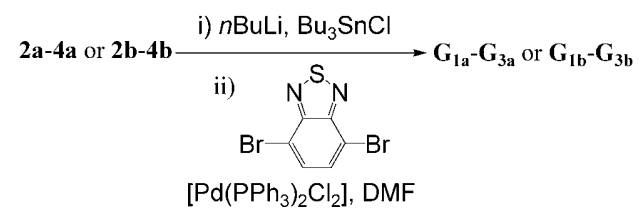

Scheme 3. Preparation of the dendrimers.

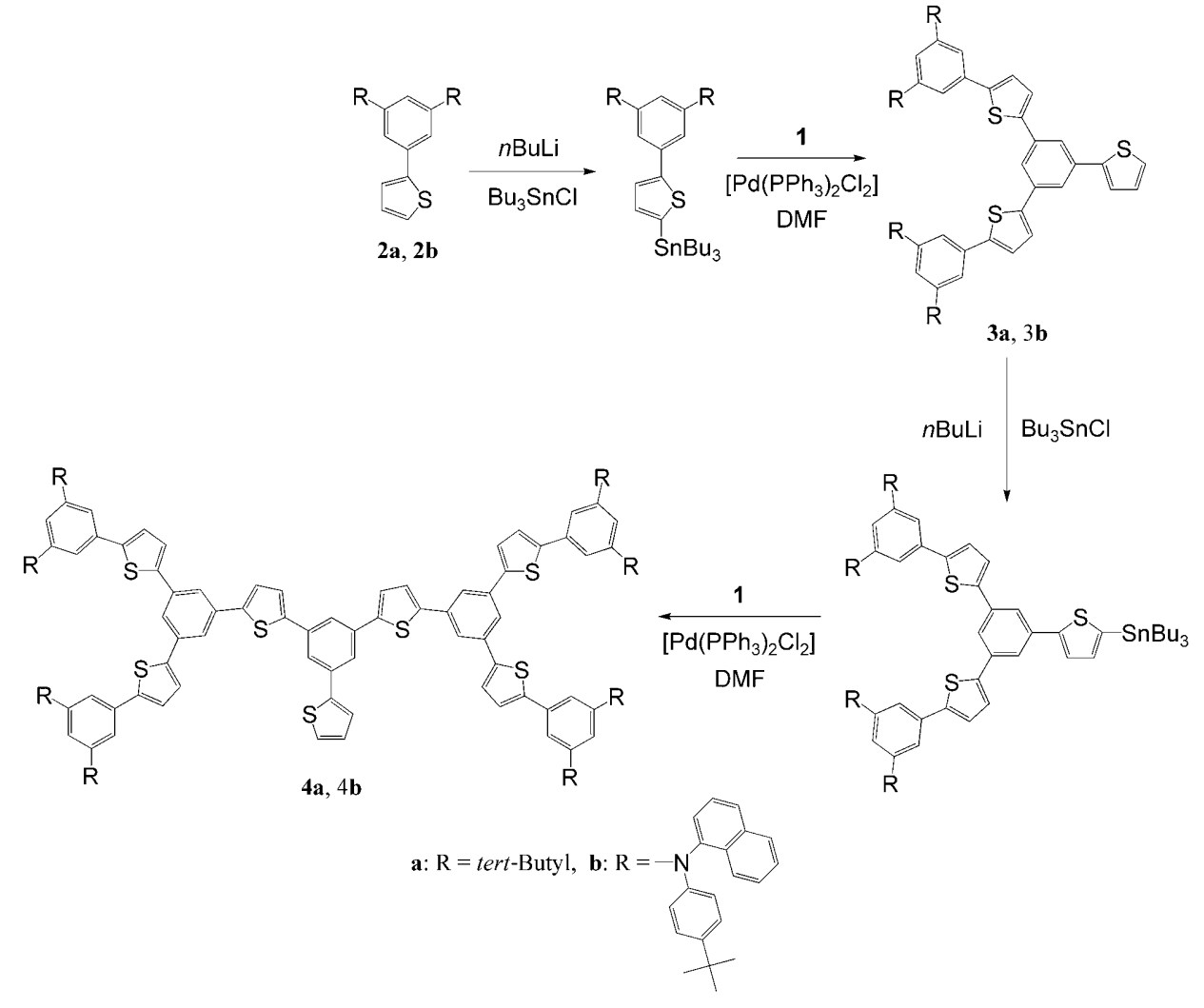

Scheme 2. Growth of the higher generation dendrons by an iterative procedure. compounds was determined by NMR $\left({ }^{1} \mathrm{H},{ }^{13} \mathrm{C}\right)$ spectroscopy, mass spectrometry, and elemental analysis.

Linear optical spectroscopy: We characterized dendrons and corresponding dendrimers by absorption and emission spectroscopy. The steady-state photophysical parameters are listed in Table 1, and the absorption and emission spectra of the dendrimers recorded in $\mathrm{CH}_{2} \mathrm{Cl}_{2}$ are displayed in Figures 1-4. The main absorption for naphthylamine dendrons $\mathbf{2 b - 4 b}$ appears at about $305 \mathrm{~nm}$ with a shoulder peaking at $345 \mathrm{~nm}$. The shoulder grows into a prominent peak for higher generations. Because the control dendrons $2 \mathbf{a}-\mathbf{4 a}$ and dendrimers $\mathbf{G}_{\mathbf{1 a}}-\mathbf{G}_{\mathbf{3 a}}$ display a single band in the lower wavelength region at about $340 \mathrm{~nm}$, it is plausible to assign the $345 \mathrm{~nm}$ 
Table 1. Physical properties of the dendrons and dendrimers.

\begin{tabular}{llll}
\hline Compd & $\lambda_{\text {abs }}[\mathrm{nm}]^{[\mathrm{a}]}$ & $T_{\mathrm{g}}\left(T_{\mathrm{m}}\right)\left[{ }^{\circ} \mathrm{C}\right]^{[\mathrm{b}]}$ & $T_{\mathrm{d}}\left[{ }^{\circ} \mathrm{C}\right]^{[\mathrm{b}, \mathrm{c}]}$ \\
\hline $\mathbf{2 a}$ & 284 & - & - \\
$\mathbf{2} \mathbf{b}$ & 294,347 & 99 & $320(331)$ \\
$\mathbf{G}_{\mathbf{1 a}}$ & 349,496 & $85(232)$ & $330(355)$ \\
$\mathbf{G}_{\mathbf{1 b}}$ & $265,304,354,499$ & 176 & $425(450)$ \\
$\mathbf{3 a}$ & 337 & $86(191)$ & $340(375)$ \\
$\mathbf{3 b}$ & 305,345 & 170 & $425(463)$ \\
$\mathbf{G}_{\mathbf{2}}$ & 346,491 & $154(366)$ & $500(530)$ \\
$\mathbf{G}_{\mathbf{2 b}}$ & $266,307,348,489$ & 201 & $427(440)$ \\
$\mathbf{4 a}_{\mathbf{4}}^{\mathbf{4}}$ & 346 & 152 & $502(530)$ \\
$\mathbf{G}_{\mathbf{3}}$ & $267,308,345$ & 197 & $450(471)$ \\
$\mathbf{G}_{\mathbf{3 b}}$ & 346,485 & 173 & $505(527)$ \\
\hline
\end{tabular}

[a] Absorption and emission spectra were recorded for dichloromethane solutions. [b] Scan rate: $10^{\circ} \mathrm{Cmin}^{-1}$. [d] Onset values and temperature at $5 \%$ weight loss in parentheses are reported.

band as originating from at least two neighboring units of the thienylbenzene backbone. As the generation increases, both the population and effective conjugation length of the thienylbenzene segment increase, so the intensity of the peak at $345 \mathrm{~nm}$ increases monotonically (Figure 1). Accordingly, the higher energy transition at $305 \mathrm{~nm}$ is attributed to the naphthyl moiety. ${ }^{[11]}$ This assignment is also supported by the linear correlation observed between the extinction coefficient at $305 \mathrm{~nm}$ and the number of naphthalene units in the dendrimer (Figure 2). The absorption spectra of the dendrimers display an additional redshifted transition at about $495 \mathrm{~nm}$, which may be attributed to conjugation of benzothiadiazole core and the neighbouring two units of thienylbenzene backbone. However, interestingly, the absorption band originating from the benzothiadiazole core of $\mathrm{G}_{1}$ dendrimers $\mathbf{G}_{\mathbf{1} \mathbf{a}}$ and $\mathbf{G}_{\mathbf{1 b}}$ is redshifted when compared to the $\mathrm{G}_{2}$ and $\mathrm{G}_{3}$ analogues. We believe that this is attributable to the proximal conjugative effect of surface groups in $G_{1}$. As the generation grows, the peripheral units are located farther

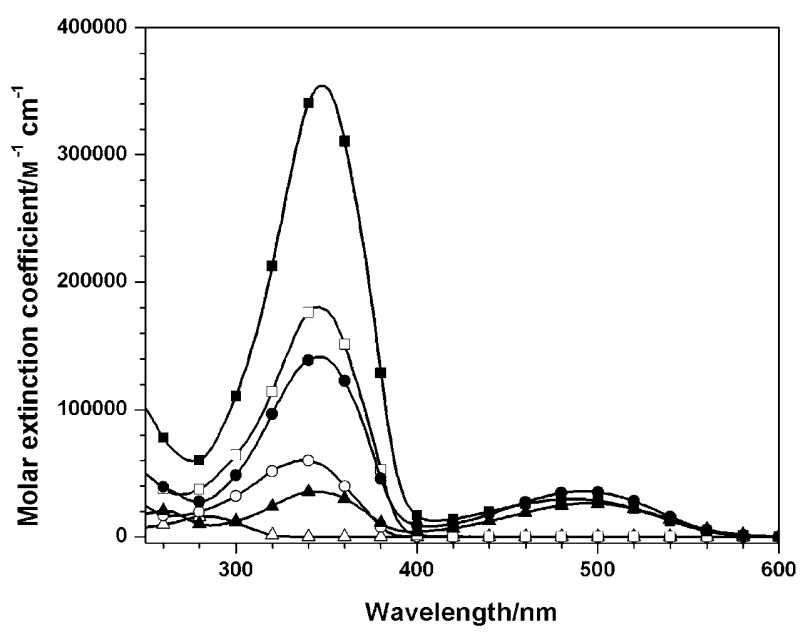

Figure 1. Absorption spectra of the control dendrons $2 \mathbf{a}(\triangle), \mathbf{3 a}(\odot), \mathbf{4 a}$ $(\square)$ and dendrimers $\mathbf{G}_{1 \mathbf{a}}(\Delta), \mathbf{G}_{2 \mathrm{a}}(\bullet), \mathbf{G}_{3 \mathrm{a}}(\boldsymbol{\bullet})$ recorded in dichloromethane.

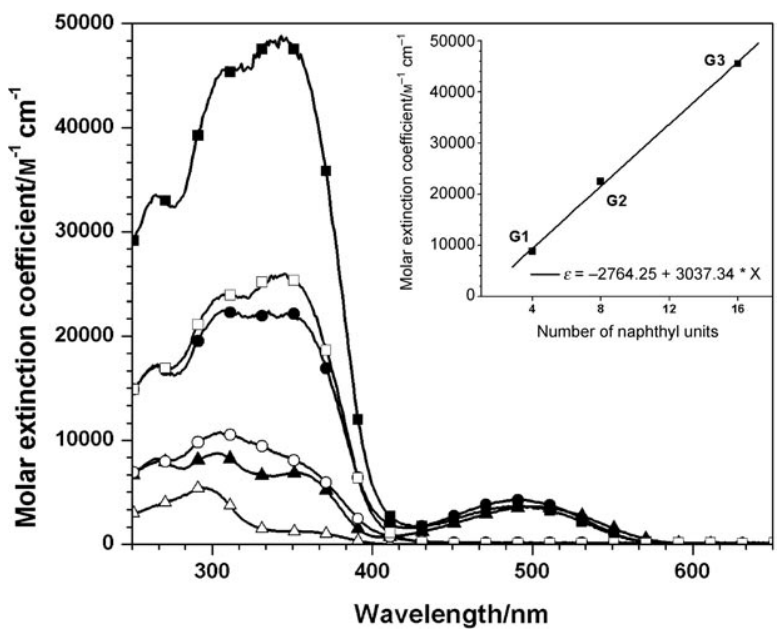

Figure 2. Absorption spectra of dendrons $2 \mathbf{b}(\triangle), \mathbf{3 b}(\circ), \mathbf{4 b}(\square)$ and naphthylamine terminated dendrimers $\mathbf{G}_{\mathbf{1 b}}(\Delta), \mathbf{G}_{\mathbf{2 b}}(\bullet), \mathbf{G}_{\mathbf{3 b}}(\bullet)$ recorded in dichloromethane. Inset shows the linear correlation of the increase in optical density $(305 \mathrm{~nm})$ due to naphthylamine units.

from the core, and significant interaction with the benzothiadiazole unit is prevented. ${ }^{[12]}$

The emission spectral features recorded for the dendrons and dendrimers in $\mathrm{CH}_{2} \mathrm{Cl}_{2}$ are presented in Figures 3 and 4, respectively. Close inspection of the emission peak positions reveals the following trends: The emission profile of the dendrons shifts bathochromically with increasing generation, while for the dendrimers the emission peak wavelength is blueshifted on growth of the dendron. These results can be plausibly explained if we first elucidate the origin of emission in dendrons and dendrimers. The dendrimers display red emission, which is characteristic of the core and corresponds to the absorption at about $495 \mathrm{~nm}$, while for the dendrons the emission seems to originate from the thienylbenzene bridges. The latter assumption is reasonable because dendrons with a higher generation should elongate the conjugation of the backbone due to the meta effect and thus result in a redshift of the emission spectral feature. A similar

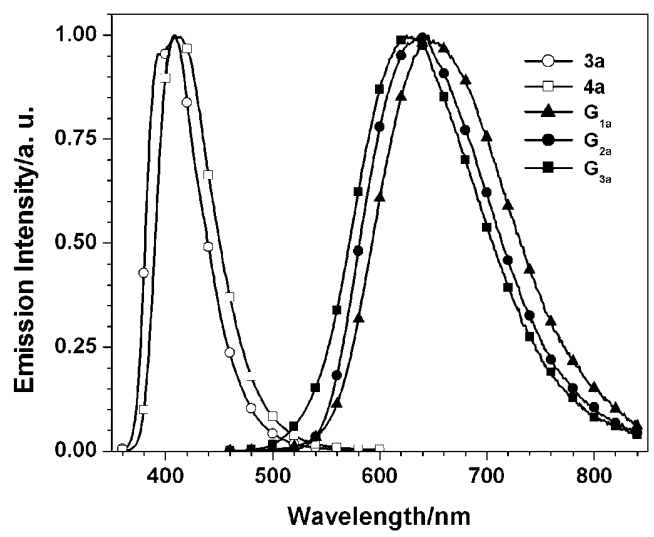

Figure 3. Normalized emission spectra of tert-butyl dendrons $\mathbf{3 a}(\bigcirc), \mathbf{4 a}$ $(\square)$ and tert-butyl dendrimers $\mathbf{G}_{\mathbf{1 a}}(\Delta), \mathbf{G}_{\mathbf{2} \mathbf{a}}(\bullet), \mathbf{G}_{\mathbf{3 a}}(\mathbf{\square})$ recorded in dichloromethane. 


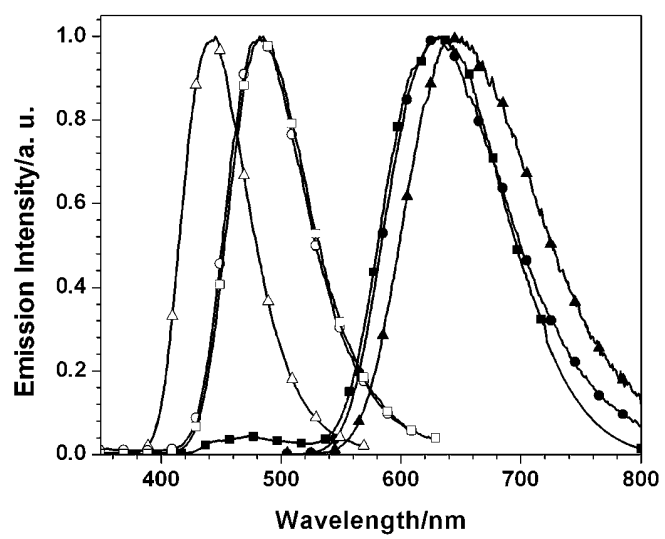

Figure 4. Normalized emission spectra of naphthylamine-containing dendrons $2 \mathbf{b}(\triangle)$, $3 \mathbf{b}(\circ), \mathbf{4 b}(\square)$ and dendrimers $\mathbf{G}_{\mathbf{1 b}}(\mathbf{\Delta}), \mathbf{G}_{\mathbf{2 b}}(\bullet), \mathbf{G}_{\mathbf{3 b}}(\mathbf{\bullet})$ recorded in dichloromethane $\left(\lambda_{\mathrm{ex}} \approx 375 \mathrm{~nm}\right)$.

effect was previously identified in meta-substituted polyacetylene dendrons and dendrimers. ${ }^{[13]}$ Conversely, on increasing the generation, the blueshift of the core emission in the dendrimers may be attributed to a combination of two factors: 1) The aforementioned proximal conjugative effect of surface groups. As the generation grows, the peripheral units are located farther from the core, and conjugative interaction with the benzothiadiazole unit is reduced. 2) Less solvent $\left(\mathrm{CH}_{2} \mathrm{Cl}_{2}\right)$ perturbation with increasing the dendron size, so that the core chromophore embedded in higher generations is subject to a more nonpolar environment.

An interesting aspect of these dendrimers is their efficient energy-harvesting behavior. As is evident in Figure 5, the emission of donor part, that is, naphthylamine in $\mathbf{2} \mathbf{b}$, overlaps well with the absorption of the parent acceptor core (as in $\mathbf{G}_{\mathbf{1 a}}$ ). This fulfils the prerequisite for efficient energy transfer according to the Förster mechanism. In accordance with this expectation, the emission peak position of dendrimers $\mathbf{G}_{\mathbf{1 b}}-\mathbf{G}_{\mathbf{3 b}}$ is fairly insensitive to the excitation wavelength, with most of the emission centered at $640 \mathrm{~nm}$ corre-

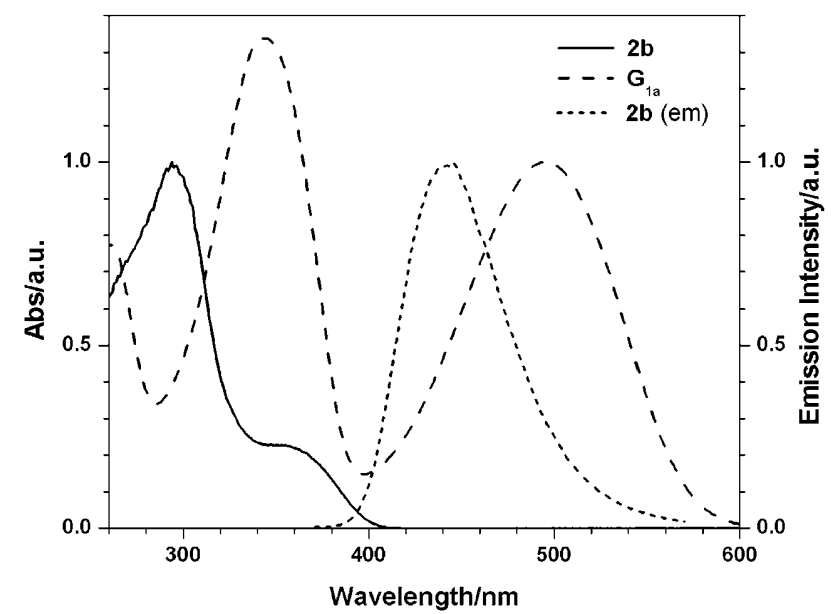

Figure 5. Spectral overlap between naphthylamine donor (2b) and core acceptor $\left(\mathbf{G}_{\mathbf{1 a}}\right)$ in dichloromethane. sponding to the dendritic core. This result provides direct evidence that efficient energy transfer takes place from the triarylamine unit at the periphery to the core. For dendrimers $\mathbf{G}_{\mathbf{1 b}}$ and $\mathbf{G}_{\mathbf{2 b}}$, negligible residual emission due to the periphery was resolved in the emission spectra on excitation at $305 \mathrm{~nm}$, which corresponds to the absorption of the surface naphthylamine groups. For $\mathbf{G}_{\mathbf{3 b}}$ a small donor-component emission (ca. $470 \mathrm{~nm}$, see Figure 4) is realized in addition to the strong, red emission of the core, that is, the energy-transfer efficiency decreases slightly in higher generations.

In a steady-state approach, we quantified the energytransfer efficiency by comparing the absorption and excitation spectrum (monitored at the emission peak) of the dendrimers. The efficiency of energy transfer can be readily deduced from the excitation spectrum of the energy acceptor. ${ }^{[11]}$ At a given wavelength, the magnitude of the excitation spectrum of the energy acceptor (A) is related to the transfer efficiency $E$ and the extinction coefficients of the energy donor $\varepsilon_{\mathrm{D}}$ and acceptor $\varepsilon_{\mathrm{A}}$ by the expression $A=\varepsilon_{\mathrm{A}}+E \varepsilon_{\mathrm{D}}$. Thus, energy-transfer efficiency was deduced to be 99,95 , and $83 \%$ for $\mathbf{G}_{\mathbf{1 b}}, \mathbf{G}_{\mathbf{2}}$, and $\mathbf{G}_{\mathbf{3 b}}$, respectively. A similar approach was used for $\mathbf{G}_{\mathbf{1 a}}-\mathbf{G}_{\mathbf{3 a}}$, and their energy-transfer efficiencies were all calculated to be near unity. Qualitatively, the results for $\mathbf{G}_{\mathbf{1 b}}-\mathbf{G}_{\mathbf{3 b}}$ seem to fit the trend documented in the literature, that is, energy-transfer efficiency decreases in higher generation dendrimers. ${ }^{[14]}$

Finally, the trend of emission quantum yield between classes $\mathbf{G}_{\mathbf{1 a}}-\mathbf{G}_{\mathbf{3 a}}$ and $\mathbf{G}_{\mathbf{1 b}}-\mathbf{G}_{\mathbf{3 b}}$ as a function of solvent polarity also attracts our attention. For example, with increasing solvent polarity from toluene to dichloromethane to dimethylformamide the acceptor (i.e., the dendritic core) emission yield decreased significantly from 0.72 to 0.23 to 0.01 , respectively, for $\mathbf{G}_{\mathbf{1 b}}$. A similar dependence of emission yield on solvent polarity was also observed for $\mathbf{G}_{\mathbf{2 b}}(0.66,0.60$, $0.06)$ and $\mathbf{G}_{\mathbf{3 b}}(0.84,0.61,0.22)$. Note that as the generation grows the magnitude of solvent effect on emission yield decreases. In contrast, the emission yield changed less significantly for $\mathbf{G}_{\mathbf{1}}-\mathbf{G}_{\mathbf{3}}$ in these three solvents (see Table 3). Owing to the low ionization potential of naphthylamine in the $G_{b}$ series, the results indicate that excited-state electron transfer may be operative for $\mathbf{G}_{\mathbf{1 b}}-\mathbf{G}_{\mathbf{3 b}}$ dendrimers. If this is the case, it is possible that dynamics of energy transfer and electron transfer are two competing pathways. To gain detailed insight into the relaxation dynamics, time-resolved studies based on the femtosecond fluorescence upconversion technique were carried out.

Transient fluorescence studies: Excited-state relaxation dynamics of the dendrons and dendrimers in toluene, dichloromethane, and dimethylformamide were measured. The three solvents were selected on the basis of their different polarity indices and sufficient solubility for all compounds under investigation, which allowed us to differentiate between the energy- and electron-transfer pathways operative in $\mathbf{G}_{\mathbf{1 b}}{ }^{-}$ $\mathbf{G}_{\mathbf{3 b}}$. The emission population lifetimes compiled in Table 2 can be summarized as follows: 1) For a given generation the excited-state lifetime of the tert-butyl dendrons $(\mathbf{2 a}-\mathbf{4 a})$ and 
Table 2. Emission properties of dendrons and dendrimers.

\begin{tabular}{|c|c|c|c|c|c|c|c|c|c|}
\hline & \multicolumn{3}{|c|}{ Toluene } & \multicolumn{3}{|c|}{ Dichloromethane } & \multicolumn{3}{|c|}{ DMF } \\
\hline & $\begin{array}{l}\lambda_{\mathrm{em}} \\
{[\mathrm{nm}]}\end{array}$ & $\begin{array}{l}\Phi_{\mathrm{f}} \\
{[\%]}\end{array}$ & $\begin{array}{l}\tau \\
{[\mathrm{ns}]}\end{array}$ & $\begin{array}{l}\lambda_{\mathrm{em}} \\
{[\mathrm{nm}]}\end{array}$ & $\begin{array}{l}\Phi_{\mathrm{f}} \\
{[\%]}\end{array}$ & $\begin{array}{l}\tau \\
{[\mathrm{ns}]}\end{array}$ & $\begin{array}{l}\lambda_{\mathrm{em}} \\
{[\mathrm{nm}]}\end{array}$ & $\begin{array}{l}\Phi_{\mathrm{f}} \\
{[\%]}\end{array}$ & $\begin{array}{l}\tau \\
{[\mathrm{ns}]}\end{array}$ \\
\hline $2 \mathbf{a}$ & & - & p..$^{[a]}$ & 360 & & 0.12 & & - & p.l. ${ }^{[a]}$ \\
\hline 2b & 420 & 0.18 & 3.03 & 443 & 0.28 & 5.30 & 442 & 0.18 & 6.23 \\
\hline $\mathbf{G}_{1 \mathrm{a}}$ & 623 & 0.72 & $6.61^{[a]}$ & 645 & 0.54 & $7.53^{[b]}$ & 660 & 0.48 & $7.08^{[a]}$ \\
\hline $\mathbf{G}_{1 \mathrm{~b}}$ & 612 & 0.70 & $5.37^{[a]}$ & 644 & 0.23 & $4.26^{[b]}$ & 662 & 0.003 & $0.04^{[a]}$ \\
\hline $3 \mathbf{a}$ & 391,408 & 0.31 & 1.89 & 408 & 0.27 & 1.77 & 412 & 0.26 & 1.44 \\
\hline 3b & 445 & 0.15 & 4.22 & 482 & 0.15 & 5.76 & 498 & 0.09 & 7.94 \\
\hline $\mathbf{G}_{2 \mathrm{a}}$ & 615 & 0.72 & $5.40^{[\mathrm{b}]}$ & 637 & 0.63 & $6.34^{[\mathrm{b}]}$ & 644 & 0.56 & $6.49^{[b]}$ \\
\hline $\mathbf{G}_{2 b}$ & 615 & 0.66 & $5.44^{[a]}$ & 630 & 0.61 & $10.57^{[\mathrm{b}]}$ & 644 & 0.06 & $1.49^{[b]}$ \\
\hline $4 a$ & 401 & 0.35 & 1.09 & 409 & 0.26 & 1.54 & 423 & 0.20 & 2.10 \\
\hline $4 b$ & 446 & 0.16 & 4.48 & 482 & 0.15 & 5.84 & 500 & 0.08 & 8.64 \\
\hline $\mathbf{G}_{3 \mathrm{a}}$ & 615 & 0.71 & $5.32^{[\mathrm{b}]}$ & 625 & 0.62 & $6.42^{[b]}$ & 642 & 0.49 & $6.59^{[\mathrm{a}]}$ \\
\hline $\mathbf{G}_{3 \mathrm{~b}}$ & 607 & 0.64 & $5.83^{[b]}$ & 630 & 0.61 & $12.01^{[\mathrm{b}]}$ & 644 & 0.22 & $4.85^{[\mathrm{a}]}$ \\
\hline
\end{tabular}

[a] Pulse limit. [b] The population decay dynamics was obtained by monitoring at the red core emission.

Table 3. Early dynamics parameters observed for the donor and acceptor emissions in dendrimers. ${ }^{[\mathrm{]}}$

\begin{tabular}{lllllll}
\hline \multicolumn{3}{c}{$\tau_{\text {donor }}($ decay dynamics $)$} & \multicolumn{2}{c}{$\tau_{\text {acceptor }}$} \\
& Toluene & $\mathrm{CH}_{2} \mathrm{Cl}_{2}$ & DMF & Toluene & $\mathrm{CH}_{2} \mathrm{Cl}_{2}$ & DMF \\
\hline $\mathbf{G}_{\mathbf{3 a}}$ & $309 \mathrm{fs}$ & $484 \mathrm{fs}$ & $352 \mathrm{fs}$ & $352 \mathrm{fs}$ & $511 \mathrm{fs}$ & $329 \mathrm{fs}$ \\
& $(0.986)$ & $(0.944)$ & $(0.964)$ & $(-0.435)$ & $(-0.486)$ & $(-0.473)$ \\
$\mathbf{G}_{\mathbf{2 b}}$ & $409 \mathrm{fs}$ & $251 \mathrm{fs}$ & $240 \mathrm{fs}$ & $216 \mathrm{fs}$ & $197 \mathrm{fs}$ & $564 \mathrm{fs}$ \\
& $(0.853)$ & $(0.932)$ & $(0.946)$ & $(-0.036)$ & $(-0.481)$ & $(-0.095)$ \\
& $12.1 \mathrm{ps}$ & $4.7 \mathrm{ps}$ & $3.4 \mathrm{ps}$ & $13.5 \mathrm{ps}$ & $3.6 \mathrm{ps}$ & $1.8 \mathrm{ps}$ \\
$\mathbf{G}_{3 \mathbf{b}}$ & $(0.147)$ & $(0.068)$ & $(0.054)$ & $(-0.332)$ & $(-0.02)$ & $(-0.015)$ \\
& $365 \mathrm{fs}$ & $352 \mathrm{fs}$ & $273 \mathrm{fs}$ & $277 \mathrm{fs}$ & $218 \mathrm{fs}$ & $253 \mathrm{fs}$ \\
& $(0.332)$ & $(0.630)$ & $(0.683)$ & $(-0.436)$ & $(-0.087)$ & $(-0.473)$ \\
$16.1 \mathrm{ps}$ & $5.9 \mathrm{ps}$ & $4.3 \mathrm{ps}$ & $15.7 \mathrm{ps}$ & $4.9 \mathrm{ps}$ & $3.8 \mathrm{ps}(-0.07)$ \\
$(0.237)$ & $(0.154)$ & $(0.230)$ & $(-0.155)$ & $(-0.216)$ & \\
\hline
\end{tabular}

[a] For clarity, the population lifetime of the acceptor is not included in this table. For dendrimers $\mathbf{G}_{\mathbf{1} \mathbf{a}}, \mathbf{G}_{\mathbf{2} \mathbf{a}}$, and $\mathbf{G}_{\mathbf{1} \mathbf{b}}$ the decay times were faster than the system response of $150 \mathrm{fs}^{-1}$.

dendrimers $\left(\mathbf{G}_{\mathbf{1 a}}-\mathbf{G}_{\mathbf{3}}\right)$ is insensitive to solvents. 2) The lifetime of the naphthylamine dendrons $(\mathbf{2 b}-\mathbf{4 b})$ increases as the solvent polarity increases from toluene to DMF. 3) For dendrimers $\mathbf{G}_{\mathbf{1 b}}-\mathbf{G}_{\mathbf{3 b}}$, a reverse trend (c.f. $\mathbf{2 b} \mathbf{- 4 b}$ ) is witnessed. For lower generation dendrimers such as $\mathbf{G}_{\mathbf{1 b}}$ the lifetime of core emission rapidly decreases with increasing solvent polarity. A similar trend was observed in higher generation dendrimers such as $\mathbf{G}_{\mathbf{2 b}}$ and $\mathbf{G}_{\mathbf{3 b}}$; however, the decrease in lifetime with changing polarity is not as significant. 4) For $\mathbf{G}_{\boldsymbol{n} \mathbf{b}}$ dendrimers, the lifetime increases in polar solvents with increasing generation, but in the nonpolar solvent toluene the excited-state lifetime remains almost the same. These observations can be rationalized by a mechanism incorporating energy- and electron-transfer processes. For the control compounds $\mathbf{G}_{\mathbf{1 a}}-\mathbf{G}_{\mathbf{3 a}}$, in which only the core acceptor unit is present, only very weak interaction of the core chromophore with the solvent and a lack of interchromophore perturbations are found. The slight alteration observed for $\mathbf{G}_{\mathbf{1 a}}$ on changing the solvent polarity can be attributed to intermolecular solute-solvent interactions. As the generation grows these intermolecular interactions are prohibited due to steric inhibition.
On the contrary, for $\mathbf{G}_{\mathbf{1 b}}-\mathbf{G}_{\mathbf{3 b}}$ excited-state electron transfer takes place from naphthylamine groups to the core chromophore, the efficiency of which, in theory, depends on coupling distance and solvent polarity. With increasing solvent polarity the energy difference between reactant (neutral species) and product (charge-transfer species) becomes larger, and hence the rate of electron transfer (emission quenching) increases. As a result, the lifetime of $\mathbf{G}_{\mathbf{1 b}}$ is significantly shortened in polar solvents. On the other hand, the electron coupling matrix is reduced, so the rate of electron transfer decreases with increasing generation, that is, donor-acceptor distance. This, in combination with the inaccessibility of the core to the solvent due to encapsulation of the core by dendritic wedges, explains the relatively insensitive solvent-polarity-dependent shortening of the lifetime for $\mathbf{G}_{\mathbf{2 b}}$ and $\mathbf{G}_{\mathbf{3 b}}$. The result differs from those recently reported for Frèchet dendrimers ${ }^{[15]}$ incorporating benzothiadiazole core and pyrenylamine peripheries, in which charge transfer from the core to the periphery is a significant quenching pathway.

Detailed fitting parameters for early-time relaxation dynamics at selected wavelengths for all studied dendrimers are listed in Table 3. Independent of the solvent, the timeresolved fluorescence of $\mathbf{G}_{\mathbf{1 a}}$ and $\mathbf{G}_{\mathbf{2}}$ monitored at less than $500 \mathrm{~nm}$, which is ascribed to the emission of the donor moiety, was established by a system-response-limited (< $150 \mathrm{fs}$ ) decay. As for $\mathbf{G}_{\mathbf{3 a}}$, the decay is also fast but resolvable and is fitted to be about $300-500 \mathrm{fs}$, depending on the solvent. These values correlate well with the early dynamics monitored at the core emission (see Table 3 ), which show instant rise ( $<150 \mathrm{fs}$ ) for $\mathbf{G}_{\mathbf{1 a}}$ and $\mathbf{G}_{\mathbf{2 a}}$ and 300-500 fs rise components for $\mathbf{G}_{\mathbf{3 a}}$. The results are consistent with data obtained from steady-state measurements, that is, energy transfer and its efficiency are approximately unity in all $G_{a}$ dendrimers.

For the $\mathrm{G}_{\mathrm{b}}$ dendrimers, the addition of a naphthylamine moiety further elongates the donor-acceptor distance. Thus, the rate of energy transfer should be suppressed, especially in the case of $\mathbf{G}_{\mathbf{3}}$, as was confirmed in the steady-state studies (vide supra). As depicted in Figure 6, the decay of the

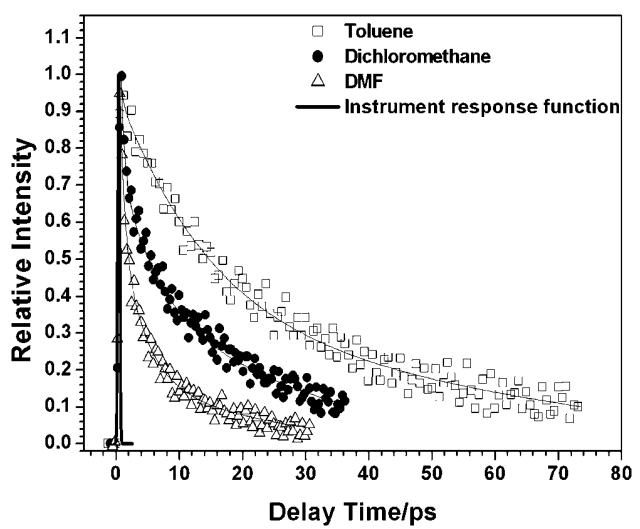

Figure 6. Decay dynamics of donor emission (monitored at $470 \mathrm{~nm}, \lambda_{\mathrm{ex}}$ $\approx 375 \mathrm{~nm}$ ) for $\mathbf{G}_{\mathbf{3 b}}$ in various solvents. 
donor moiety of $\mathbf{G}_{\mathbf{3 b}}$ (i.e., naphthylamine, monitored at $470 \mathrm{~nm}$ ) consists of a component with a few hundred femtoseconds and a fast but resolvable component on the order of several to tens of picoseconds. The ultrafast decay component is nearly at the system response limit; therefore, the fitted time constant listed in Table 3 should not be treated as a trend to correlate with the solvent parameters. However, its value, to a certain extent, seems to reveal solvent dependency. On the other hand, the fast decay component of a few picoseconds is evidently dependent on solvent polarity; it decreases from $16.1 \mathrm{ps}$ in toluene to $4.3 \mathrm{ps}$ in DMF. Moreover, the picosecond decay component correlates well with the rise component of the core emission (monitored at $655 \mathrm{~nm}$, see Figure 7 and Table 3), which was measured to

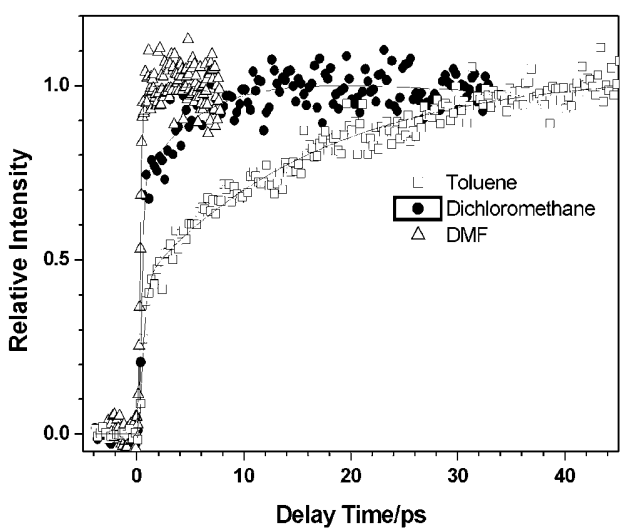

Figure 7. Rise dynamics of acceptor emission (monitored at $655 \mathrm{~nm}, \lambda_{\text {ex }}$ $\approx 375 \mathrm{~nm}$ ) for $\mathbf{G}_{\mathbf{3 b}}$ in various solvents.

be $15.7,4.9$, and 3.8 ps in toluene, $\mathrm{CH}_{2} \mathrm{Cl}_{2}$ and $\mathrm{DMF}$, respectively. This result clearly indicates a precursor-successor type of relationship between donor and acceptor moieties. We thus attribute this picosecond decay component to energy dissipation of the excited donor moiety through energy/electron transfer to the core (acceptor) moiety. As such, it is reasonable to ascribe the decay component on a timescale of a few hundred femtoseconds to vibrational and/ or solvent relaxation dynamics following Franck-Condon excitation. Note that, on monitoring at $655 \mathrm{~nm}$ (see Figure 7), in addition to the picosecond rise component, a certain system-response-limited rise component is attributed to direct core excitation. Similar results were obtained for $\mathbf{G}_{\mathbf{2 b}}$, except that the relaxation dynamics of the donor are faster (12.1, 4.7 and $3.4 \mathrm{ps}$ in toluene, $\mathrm{CH}_{2} \mathrm{Cl}_{2}$ and DMF, respectively; see Figure 8 and Table 3 ). First-generation $\mathbf{G}_{\mathbf{1 b}}$ exhibits a system-response-limited $(<150 \mathrm{fs})$ decay for the donor moiety in three studied solvents, consistent with the trend of transfer efficiency of $\mathbf{G}_{\mathbf{3 b}}<\mathbf{G}_{\mathbf{2 b}}<\mathbf{G}_{\mathbf{1 b}}$ deduced from steady-state studies (vide supra).

Thermal properties: The thermal properties of the compounds were studied by both thermogravimetric analysis and differential scanning calorimetry measurements (see

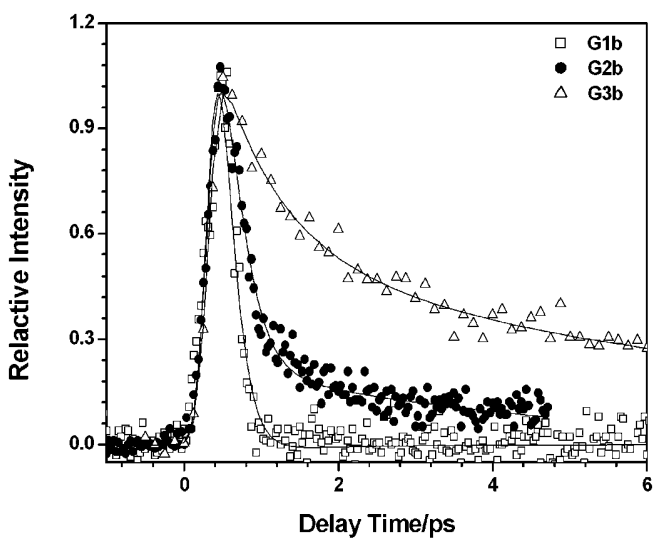

Figure 8. Decay dynamics of donor emission (monitored at $470 \mathrm{~nm}, \lambda_{\mathrm{ex}}$ $\approx 375 \mathrm{~nm}$ ) for $\mathbf{G}_{\mathbf{1 b}}, \mathbf{G}_{\mathbf{2}}$, and $\mathbf{G}_{\mathbf{3 b}}$ in DMF.

Table 1 for relevant parameters). The glass transition temperature for the dendrons and tert-butyl dendrimers $\mathbf{G}_{\mathbf{1 a}}-\mathbf{G}_{\mathbf{3 a}}$ gradually increases with increasing generation. However, for the functional dendrimers, after a initial raise in $T_{\mathrm{g}}$ for $\mathbf{G}_{\mathbf{2 b}}$, a slight decrease in $T_{\mathrm{g}}$ is observed for $\mathbf{G}_{\mathbf{3 b}}$. This is probably due to the mobility induced by the voluminous structure of $\mathbf{G}_{\mathbf{3 b}}$. In general, the glass transition temperatures observed for the dendrimers are higher when compared to commonly employed amorphous electroluminescent materials 1,4bis(1-naphthylphenylamino)biphenyl (NPB) and 1,4-bi$\mathrm{s}$ (phenyl- $m$-tolylamino)biphenyl (TPD).$^{[16]}$

Electrochemical and electroluminescence studies: Electrochemical studies revealed that the dendrimers are bipolar in nature. Oxidation due to the peripheral amine groups and reduction due to the central benzothiadiazole core were observed in the cyclic voltammograms of the dendrimers at about 0.4 and $-1.7 \mathrm{~V}$ respectively (Table 4 ). For the $\mathbf{G}_{\mathbf{3} \mathbf{b}}$

Table 4. Redox properties of the amino-substituted dendrons and dendrimers.

\begin{tabular}{lllll}
\hline compd & $E_{\text {ox }}\left(\Delta E_{\mathrm{p}}\right)[\mathrm{mV}]^{[\mathrm{a}]}$ & $E_{\text {red }}[\mathrm{mV}]^{[\mathrm{a}]}$ & HOMO $[\mathrm{eV}]^{[\mathrm{b}]}$ & LUMO $[\mathrm{eV}]$ \\
\hline $\mathbf{2 b}$ & $389(55)$ & - & 5.189 & - \\
$\mathbf{G}_{\mathbf{1 b}}$ & $430(86)$ & $-1697(70)$ & 5.230 & 3.103 \\
$\mathbf{3 b}$ & $430(85)$ & - & 5.230 & - \\
$\mathbf{G}_{\mathbf{2 b}}$ & $437(83)$ & $-1656(63)$ & 5.237 & 3.144 \\
$\mathbf{4 b}$ & $420(108)$ & - & 5.220 & - \\
$\mathbf{G}_{\mathbf{3 b}}$ & $421(89)$ & $-1716(\mathrm{i})$ & 5.221 & 3.084
\end{tabular}

[a] Potentials are quoted with reference to ferrocene as internal standard; scan rate: $100 \mathrm{mVs}^{-1}$; i: irreversible. [b] Frontier orbital energies were deduced from $E_{\text {orb }}=4.8+E_{\text {ox/red }}$.

benzothiadiazole reduction is irreversible, possibly due to inaccessibility of the core at the electrode surface. This socalled dendritic effect has been well documented for a wide array of redox-responsive dendrimers. ${ }^{[17]}$ The HOMO and LUMO energies derived from the redox potentials are on the order of 5.2 and $3.1 \mathrm{eV}$ respectively.

All the aforementioned properties make these dendrimers attractive candidates for electroluminescence applications. 
Since dendrimers $\mathbf{G}_{\mathbf{1 b}}$ and $\mathbf{G}_{\mathbf{2}}$ exhibit good thermal stability, vapor deposition was successful for these two compounds despite their high molecular weights. Two types of devices were made from the above two dendrimers: 1) ITO/ $\mathbf{G}_{\mathbf{1 b}}$ or $\mathbf{G}_{\mathbf{2}} / \mathrm{TPBI} / \mathrm{LiF} / \mathrm{Al}$ and 2) ITO/NPB/G $\mathbf{G}_{\mathbf{1 b}}$ or $\mathbf{G}_{\mathbf{2} \mathbf{b}} / \mathrm{TPBI} / \mathrm{LiF} / \mathrm{Al}$ $(\mathrm{ITO}=$ indium tin oxide, TPBI $=1,3,5$-tris $(N$-phenylbenzimidazol-2-yl)benzene). The triple-layer devices were found be better than the double-layer devices in all respects. This indicates that better balance in charge transport and more efficient recombination are achieved with an additional holetransporting layer consisting of NPB. The $I-V-L$ curves for the devices are displayed in Figure 9. The devices fabricated from $\mathbf{G}_{\mathbf{1 b}}$ displayed pure red emission with chromaticity coordinates $x=0.61, y=0.34$, maximum luminance of $8500 \mathrm{~cd} \mathrm{~m}^{-2}$, and external quantum efficiency of $1.84 \%$ at a current density of $20 \mathrm{mAcm}^{-2}$.

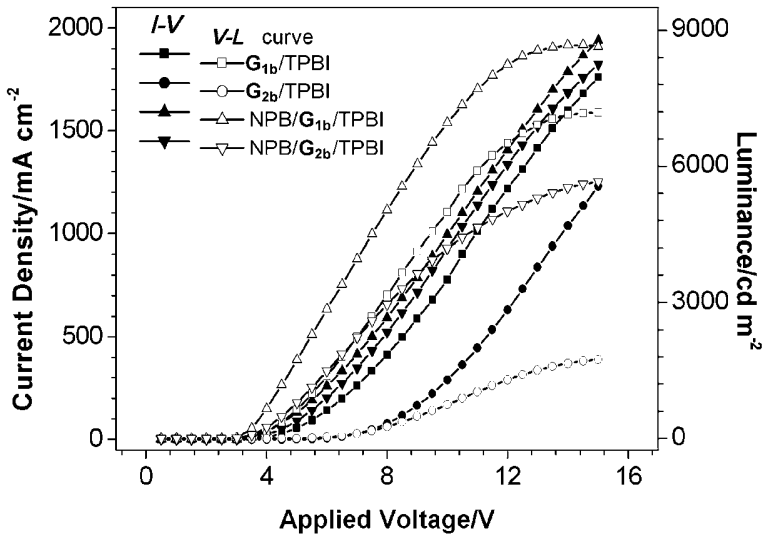

Figure 9. $I-V-L$ characteristics observed for the devices fabricated with dendrimers $\mathbf{G}_{\mathbf{1 b}}$ and $\mathbf{G}_{\mathbf{2 b}}$.

\section{Conclusion}

In summary, we have designed and synthesized new redemitting dendrimers with thienylbenzene backbones, naphthylamine peripheries, and benzothiadiazole cores. These donor-acceptor molecules exhibit efficient energy transfer and are highly luminescent red fluorophores. Energy-transfer dynamics, monitored by transient fluorescence studies, reveal that these rigid meta-substituted dendrimers are significantly different from flexible dendrimers having similar donor-acceptor architecture (benzothiadiazole/triarylamine) and Frèchet branches. Additionally, their amorphous nature with high glass transition temperatures $\left(176-201^{\circ} \mathrm{C}\right)$ opens an avenue for application in electroluminescent devices.

\section{Experimental Section}

General information: All reactions and manipulations were carried out under $\mathrm{N}_{2}$ by standard inert-atmosphere and Schlenk techniques. Solvents were dried by standard procedures. All column chromatography was performed under $\mathrm{N}_{2}$ on silica gel (230-400 mesh, Macherey-Nagel GmbH \&
Co.) as stationary phase in a column $30 \mathrm{~cm}$ long and $2.0 \mathrm{~cm}$ in diameter. The ${ }^{1} \mathrm{H}$ NMR spectra were measured on a Bruker AC300 or AMX400 spectrometer. Mass spectra were recorded on a JMS-700 double-focusing mass spectrometer (JEOL, Tokyo, Japan). Elemental analyses were performed on a Perkin-Elmer $2400 \mathrm{CHN}$ analyzer. Cyclic voltammetry experiments were performed with a BAS-100 electrochemical analyzer. All measurements were carried out at room temperature with a conventional three-electrode configuration consisting of a glassy carbon working electrode, a platinum wire auxiliary electrode, and a nonaqueous $\mathrm{Ag} / \mathrm{AgNO}_{3}$ reference electrode. The $E_{1 / 2}$ values were determined as $\left(E_{\mathrm{p}}^{\mathrm{a}}+E_{\mathrm{p}}^{\mathrm{c}}\right) / 2$, where $E_{\mathrm{p}}^{\mathrm{a}}$ and $E_{\mathrm{p}}^{\mathrm{c}}$ are the anodic and cathodic peak potentials, respectively. The potentials are quoted against ferrocene internal standard. The solvent in all experiments was dichloromethane and the supporting electrolyte was $0.1 \mathrm{~m}$ tetrabutylammonium hexafluorophosphate. Electronic absorption spectra were obtained with a Perkin Elmer Lambda 900 UV/ Vis/NIR spectrophotometer on dichloromethane solutions. Emission spectra were recorded in deoxygenated solutions at $298 \mathrm{~K}$ with a Jobin Yvon SPEX Fluorolog-3 spectrofluorometer. The emission spectra were collected on samples with o.d. $<0.1$ at the excitation wavelength. The spectra were corrected for instrumental response. UV/Vis spectra were checked before and after irradiation to monitor possible sample degradation. Emission maxima were reproducible to within $2 \mathrm{~nm}$. Luminescence quantum yields $\Phi_{\mathrm{em}}$ were calculated by using Coumarin 1 as primary standard ( $\Phi_{\mathrm{em}}=0.99$ in ethyl acetate) for blue fluorophores or 4-dicyanomethylene-2-methyl-6- $p$-diethylaminostyryl-4- $H$-pyran $\left(\mathrm{DCM}, \Phi_{\mathrm{em}}=0.40\right.$ in acetonitrile) as secondary reference for red fluorophores. ${ }^{[1]}$

Nanosecond lifetime studies were performed with an Edinburgh FL 900 photon-counting system with a hydrogen-filled or nitrogen lamp as excitation source. The emission decays were analyzed by the sum of exponential functions, which allows partial removal of instrument time broadening and consequently affords a temporal resolution of about $200 \mathrm{ps}$. The setup of picosecond dynamical measurements consists of a femtosecond Ti:sapphire oscillator ( $82 \mathrm{MHz}$, Spectra Physics). The fundamental train of pulses was pulse-selected (Neos, model N17389) to reduce its repetition rate to typically $0.8-8 \mathrm{MHz}$, and then used to produce second harmonics $(375-425 \mathrm{~nm})$ as an excitation light source. A polarizer was placed in the emission path to ensure that the polarization of the fluorescence was set at the magic angle $\left(54.7^{\circ}\right)$ with respect to the pump laser to eliminate fluorescence anisotropy. An Edinburgh OB 900 L time-correlated single-photon counting system was used as detector, with a temporal resolution of about $15 \mathrm{ps}$. The fluorescence upconversion measurements were performed by using a femtosecond optically gated system (FOG-100, CDP). The fundamental of a Ti:sapphire laser (Spectra Physics) at $750-850 \mathrm{~nm}$ with an average power of $0.5 \mathrm{~W}$ and a repetition rate of $82 \mathrm{MHz}$ was used to produce second harmonics $(\mathrm{SH})$ at $375-425 \mathrm{~nm}$ by focusing onto a $0.5 \mathrm{~mm}$-thick BBO type-I crystal. The $\mathrm{SH}$ was then separated from the fundamental pulses with a dichroic mirror and used as pump pulses. The pump pulses were focused onto a rotating cell, and the optical path length was $1.0 \mathrm{~mm}$. The resulting fluorescence was collected by an achromatic lens and then focused on another BBO type-I crystal $(0.5 \mathrm{~mm})$. The optically delayed remaining fundamental pulses were also focused on the BBO crystal and used as gate pulses for sumfrequency generation. A half-wave plate was placed in the pump beam path to ensure that the polarization of the pump laser was set at the magic angle $\left(54.7^{\circ}\right)$ with respect to the probe laser to eliminate fluorescence anisotropy. The up-converted signal was then separated by an $F / 4.9$ $(f=380 \mathrm{~mm})$ single monochromator (CDP2022) and detected by a photon-counting photomultiplier tube (R1527P, Hamamatsu). The crosscorrelation between $\mathrm{SH}$ and the fundamental had a full width at halfmaximum (fwhm) of about $150 \mathrm{fs}$, which was chosen as a response function of the system.

2-(3,5-Dibromophenyl)thiophene (1): A mixture of 1,3,5-tribromobenzene $(3.15 \mathrm{~g}, 10 \mathrm{mmol})$, 2-thienylmagnesium bromide $(1.87 \mathrm{~g}, 10 \mathrm{mmol}$, freshly prepared from 2-bromothiophene and magnesium), [Pd$\left.\left(\mathrm{PPh}_{3}\right)_{2} \mathrm{Cl}_{2}\right](70 \mathrm{mg})$, and tetrahydrofuran $(70 \mathrm{~mL})$ was heated at $70^{\circ} \mathrm{C}$ for $24 \mathrm{~h}$. After cooling, the reaction mixture was poured into ice water. It was extracted with diethyl ether and evaporated to leave a tan solid, which was adsorbed on silica gel and subjected to column chromatography. After the first fraction containing the unconverted 1,3,5-tribromo- 
benzene the desired compound was eluted with hexanes. Colorless solid. Yield: $1.34 \mathrm{~g}(42 \%) .{ }^{1} \mathrm{H}$ NMR $\left(300 \mathrm{MHz}, \mathrm{CDCl}_{3}, 25^{\circ} \mathrm{C}\right): \delta=7.07$ (t, $J=$ $4.7 \mathrm{~Hz}, 1 \mathrm{H}), 7.28(\mathrm{~d}, J=3.5 \mathrm{~Hz}, 1 \mathrm{H}), 7.32(\mathrm{~d}, J=4.7 \mathrm{~Hz}, 1 \mathrm{H}), 7.54(\mathrm{t}, J=$ $2.1 \mathrm{~Hz}, 1 \mathrm{H}), 7.64 \mathrm{ppm}(\mathrm{d}, J=2.1 \mathrm{~Hz}, 2 \mathrm{H}) ;{ }^{13} \mathrm{C} \mathrm{NMR}\left(75 \mathrm{MHz}, \mathrm{CDCl}_{3}\right.$, $25^{\circ} \mathrm{C}$ ): $\delta=123.3,124.6,126.4,127.5,128.2,132.5,137.7,140.9 \mathrm{ppm}$; HREIMS calcd for $\mathrm{C}_{10} \mathrm{H}_{6} \mathrm{Br}_{2} \mathrm{~S}$ : 315.8557; found: 315.8556 .

$\boldsymbol{N}$-(4-tert-Butylphenyl)naphthalen-1-amine: A mixture of naphthalen-1amine $(1.72 \mathrm{~g}, 12 \mathrm{mmol}), 1$-tert-butyl-4-bromobenzene $(2.13 \mathrm{~g}, 10 \mathrm{mmol})$, $\left[\mathrm{Pd}(\mathrm{dba})_{2}\right](58 \mathrm{mg}), t \mathrm{Bu}_{3} \mathrm{P}(30 \mathrm{mg}), t \mathrm{BuONa}(1.44 \mathrm{~g}, 15 \mathrm{mmol})$ and toluene $(30 \mathrm{~mL})$ was stirred at room temperature overnight. After the reaction was complete, as evidenced by the disappearance of 1-tert-butyl-4bromobenzene, it was quenched by addition of water and extracted with diethyl ether. The organic extracts were collected, washed with brine, and evaporated to leave a pale yellow syrup. It was purified by column chromatography on silica gel by eluting with hexanes/dichloromethane (3/1). Colorless solid. Yield: $2.4 \mathrm{~g} \quad(87 \%) .{ }^{1} \mathrm{H}$ NMR $\quad(300 \mathrm{MHz}$, [D $\mathrm{D}_{6}$ ]acetone, $\left.25^{\circ} \mathrm{C}\right): \delta=1.30(\mathrm{~s}, 9 \mathrm{H}), 7.07(\mathrm{~d}, J=8.5 \mathrm{~Hz}, 2 \mathrm{H}), 7.29-7.51$ $(\mathrm{m}, 8 \mathrm{H}), 7.86(\mathrm{~d}, J=8.1 \mathrm{~Hz}, 1 \mathrm{H}), 8.20 \mathrm{ppm}(\mathrm{d}, J=8.5 \mathrm{~Hz}, 1 \mathrm{H}) ;{ }^{13} \mathrm{C} \mathrm{NMR}$ (75 MHz, $\left[\mathrm{D}_{6}\right]$ acetone, $\left.25^{\circ} \mathrm{C}\right): \delta=31.8,34.6,114.3,118.6,122.1,123.1$, $125.8,126.6,126.7,126.9,128.1,129.1,135.8,141.1,143.2,143.7 \mathrm{ppm}$; HREIMS calcd for $\mathrm{C}_{20} \mathrm{H}_{21} \mathrm{~N}$ : 275.1674; found: 275.1671 .

2-(3,5-Di-tert-butylphenyl)thiophene (2a): A solution of 3,5-di-tert-butylphenyl trifluoromethanesulfonate $(3.38 \mathrm{~g}, 10 \mathrm{mmol})$, thiophen-2-ylmagnesium bromide $(2.25 \mathrm{~g}, 12 \mathrm{mmol}$, freshly prepared from 2-bromothiophene and magnesium), $\left[\mathrm{Pd}\left(\mathrm{PPh}_{3}\right)_{2} \mathrm{Cl}_{2}\right](70 \mathrm{mg}, 0.1 \mathrm{mmol})$, and tetrahydrofuran was refluxed under nitrogen atmosphere for $24 \mathrm{~h}$. After cooling, the reaction mixture was quenched with ice water and extracted with diethyl ether $(3 \times 50 \mathrm{~mL})$. The combined organic extract was dried over anhydrous $\mathrm{MgSO}_{4}$ and evaporated to dryness to leave a colorless viscous liquid. It was purified by column chromatography on silica gel with hexanes as eluant. Yield: $2.12 \mathrm{~g}(78 \%) .{ }^{1} \mathrm{H}$ NMR $\left(300 \mathrm{MHz}, \mathrm{CDCl}_{3}, 25^{\circ} \mathrm{C}\right)$ : $\delta=1.35(\mathrm{~s}, 18 \mathrm{H}), 7.05-7.08(\mathrm{~m}, 1 \mathrm{H}), 7.24-7.29(\mathrm{~m}, 2 \mathrm{H}), 7.36(\mathrm{~d}, J=$ $3.8 \mathrm{~Hz}, 1 \mathrm{H}), 7.43 \mathrm{ppm}(\mathrm{d}, J=1.8 \mathrm{~Hz}, 1 \mathrm{H}) ;{ }^{13} \mathrm{C} \mathrm{NMR}\left(75 \mathrm{MHz}, \mathrm{CDCl}_{3}\right.$, $\left.25^{\circ} \mathrm{C}\right): \delta=31.4,34.9,120.7,121.8,122.8,124.3,127.8,133.7,145.7$, $151.3 \mathrm{ppm}$; HREIMS calcd for $\mathrm{C}_{18} \mathrm{H}_{24} \mathrm{~S}: 272.4482$; found: 272.4474

$N^{1}, N^{3}$-Bis(4-tert-butylphenyl)- $\boldsymbol{N}^{1}, \boldsymbol{N}^{3}$-bis(naphthalen-1-yl)-5-(thiophen-2yl)benzene-1,3-diamine (2b): A mixture of 2-(3,5-dibromophenyl)thiophene $\quad(3.18 \mathrm{~g}, \quad 10 \mathrm{mmol}), \quad N$-(4-tert-butylphenyl)naphthalen-1-amine $(5.78 \mathrm{~g}, 21 \mathrm{mmol}),\left[\mathrm{Pd}(\mathrm{dba})_{2}\right](116 \mathrm{mg}), t \mathrm{Bu}_{3} \mathrm{P}(60 \mathrm{mg}), t \mathrm{BuONa}(2.88 \mathrm{~g}$, $30 \mathrm{mmol}$ ), and toluene $(40 \mathrm{~mL})$ was stirred at $80^{\circ} \mathrm{C}$ overnight. After quenching with water, it was extracted with diethyl ether. The combined organic extracts were dried over anhydrous $\mathrm{MgSO}_{4}$ and evaporated to dryness to yield a pale yellow solid. It was purified by column chromatography on silica gel with hexanes/dichloromethane (4/1) as eluant. Pale yellow solid. Yield: $6.1 \mathrm{~g}(86 \%) .{ }^{1} \mathrm{H}$ NMR $\left(300 \mathrm{MHz}, \mathrm{CDCl}_{3}, 25^{\circ} \mathrm{C}\right): \delta=$ $1.27(\mathrm{~s}, 18 \mathrm{H}), 6.50(\mathrm{t}, J=2.1 \mathrm{~Hz}, 1 \mathrm{H}), 6.72(\mathrm{~d}, J=2.1 \mathrm{~Hz}, 2 \mathrm{H}), 6.83-6.88$ $(\mathrm{m}, 5 \mathrm{H}), 6.92-6.93(\mathrm{~m}, 1 \mathrm{H}), 7.02-7.08(\mathrm{~m}, 5 \mathrm{H}), 7.29(\mathrm{~d}, J=7.1 \mathrm{~Hz}, 2 \mathrm{H})$, 7.36-7.41 (m, 4H), $7.48(\mathrm{t}, J=7.1 \mathrm{~Hz}, 2 \mathrm{H}), 7.69(\mathrm{~d}, J=8.1 \mathrm{~Hz}, 2 \mathrm{H}), 7.87$ $(\mathrm{d}, J=8.1 \mathrm{~Hz}, 2 \mathrm{H}), 7.95 \mathrm{ppm}(\mathrm{d}, J=8.5 \mathrm{~Hz}, 2 \mathrm{H}) ;{ }^{13} \mathrm{C} \mathrm{NMR}(75 \mathrm{MHz}$, $\left.\mathrm{CDCl}_{3}, 25^{\circ} \mathrm{C}\right): \delta=31.4,34.1,111.3,112.8,121.8,123.1,124.3,124.4,125.6$, 125.9, 126.2, 127.0, 127.5, 128.3, 131.2, 135.2, 125.6, 143.2, 144.6, 144.7, 145.1, $149.4 \mathrm{ppm}$; FABMS: $\mathrm{m} / \mathrm{z} 707.2[\mathrm{M+H}]^{+}$; elemental analysis calcd (\%) for $\mathrm{C}_{50} \mathrm{H}_{46} \mathrm{~N}_{2} \mathrm{~S}$ : C 84.94, H 6.56, N 3.96; found: C 84.75, H 6.69, N 3.88

4,7-Bis[5-(3,5-di-tert-butylphenyl] thiophen-2-yl)benzo[ $[c][1,2,5]$ thiadiazole $\left(\mathbf{G}_{\mathbf{1 a}}\right)$ : A solution of 2-(3,5-di-tert-butylphenyl)thiophene (2.73 g, $10 \mathrm{mmol})$ in tetrahydrofuran $(50 \mathrm{~mL})$ was cooled to $-75^{\circ} \mathrm{C}$ and $n$-butyl lithium $(6.9 \mathrm{~mL}, 1.6 \mathrm{M}$ in hexanes, $11 \mathrm{mmol})$ added dropwise over $10 \mathrm{~min}$. After stirring at this temperature for $30 \mathrm{~min}$, it was again cooled to $-75^{\circ} \mathrm{C}$. Tributyltin chloride $(3.58 \mathrm{~g}, 11 \mathrm{mmol})$ was added and the mixture allowed to stir at room temperature overnight. It was quenched by addition of ice water and extracted with diethyl ether. The combined organic extracts were dried over anhydrous $\mathrm{MgSO}_{4}$ and evaporated to dryness to leave the stannylene derivative. It was immediately mixed with 4,7-dibromobenzothiadiazole $(1.47 \mathrm{~g}, 5 \mathrm{mmol}),\left[\mathrm{Pd}_{(}\left(\mathrm{PPh}_{3}\right)_{2} \mathrm{Cl}_{2}\right](35 \mathrm{mg})$, and DMF $(15 \mathrm{~mL})$. The resulting mixture was heated at $80^{\circ} \mathrm{C}$ for $18 \mathrm{~h}$. A red solid formed. After cooling the mixture, methanol $(40 \mathrm{~mL})$ was added to complete the precipitation. The solids were filtered and washed with liberal amounts of methanol. The red solid obtained was dissolved in $\mathrm{CH}_{2} \mathrm{Cl}_{2}$ and subjected to column chromatography on silica gel. The desired compound was obtained by elution with hexanes/dichloromethane (2/1) in $67 \%$ yield. ${ }^{1} \mathrm{H}$ NMR $\left(400 \mathrm{MHz}, \mathrm{CDCl}_{3}, 25^{\circ} \mathrm{C}\right): \delta=1.38(\mathrm{~s}, 36 \mathrm{H}), 7.39$ $7.41(\mathrm{~m}, 4 \mathrm{H}), 7.53(\mathrm{~d}, J=1.8 \mathrm{~Hz}, 4 \mathrm{H}), 7.89(\mathrm{~s}, 2 \mathrm{H}), 8.13 \mathrm{ppm}(\mathrm{d}, J=$ $3.8 \mathrm{~Hz}, 2 \mathrm{H}) ;{ }^{13} \mathrm{C}$ NMR $\left(100 \mathrm{MHz}, \mathrm{CDCl}_{3}, 25^{\circ} \mathrm{C}\right): \delta=31.5,35.0,120.5$, $122.3,123.9,125.2,125.8,128.6,133.5,128.3,146.8,151.4,152.6 \mathrm{ppm}$; FABMS: $m / z 676.2[M]^{+}$; elemental analysis calcd $(\%)$ for $\mathrm{C}_{42} \mathrm{H}_{48} \mathrm{~N}_{2} \mathrm{~S}_{3}: \mathrm{C}$ 74.51, H 7.15, N 4.14; found: C 74.32, H 7.03, N 4.20.

5-\{5-[4-(5-\{3,5-Bis[ $N$-(4-tert-butylphenyl)- $N$-(naphthalen-1-yl)amino]phenyl) thiophen-2-yl)benzo[c][1,2,5]thiadiazol-7-yl] thiophen-2-yl\}- $N^{1}, N^{3}$ bis(4-tert-butylphenyl)- $\boldsymbol{N}^{1}, N^{3}$-bis(naphthalen-1-yl)benzene-1,3-diamine $\left(\mathbf{G}_{1 \mathbf{b}}\right)$ : A mixture of dendron $\mathbf{2 b}(2.83 \mathrm{~g}, 4 \mathrm{mmol})$ and tetrahydrofuran $(50 \mathrm{~mL})$ was cooled to $-75^{\circ} \mathrm{C}$, and $n$-butyl lithium $(2.8 \mathrm{~mL}, 1.6 \mathrm{M}$ in hexanes) added dropwise over $10 \mathrm{~min}$. Over $1 \mathrm{~h}$ it was slowly allowed to warm to $0^{\circ} \mathrm{C}$. After stirring at this temperature for $30 \mathrm{~min}$, it was again cooled to $-75^{\circ} \mathrm{C}$. Tributyltin chloride $(1.63 \mathrm{~g}, 5 \mathrm{mmol})$ was added and the mixture allowed to stir at room temperature overnight. It was quenched by addition of ice water and extracted with diethyl ether. The combined organic extracts were dried over anhydrous $\mathrm{MgSO}_{4}$ and evaporated to dryness to leave the stannylene derivative. It was immediately mixed with 4,7-dibromobenzothiadiazole $(0.53 \mathrm{~g}, 1.8 \mathrm{mmol}), \quad\left[\mathrm{Pd}\left(\mathrm{PPh}_{3}\right)_{2} \mathrm{Cl}_{2}\right]$ $(14 \mathrm{mg})$, and DMF $(10 \mathrm{~mL})$. The resulting mixture was heated at $80^{\circ} \mathrm{C}$ for $18 \mathrm{~h}$. A red solid formed. After cooling the mixture, methanol $(40 \mathrm{~mL})$ was added to complete the precipitation. The solids were collected by filtration and washed with liberal amounts of methanol. The red solid obtained was dissolved in $\mathrm{CH}_{2} \mathrm{Cl}_{2}$ and subjected to column chromatography on silica gel. The desired compound was obtained by elution with hexanes/dichloromethane (1/1). Yield: $2.0 \mathrm{~g} \quad(72 \%)$. ${ }^{1} \mathrm{H}$ NMR $\left(400 \mathrm{MHz}, \mathrm{CDCl}_{3}, 25^{\circ} \mathrm{C}\right): \delta=1.24(\mathrm{~s}, 36 \mathrm{H}), 6.44(\mathrm{t}, J=2.1 \mathrm{~Hz}, 2 \mathrm{H}), 6.76$ $(\mathrm{d} J=2.1 \mathrm{~Hz}, 4 \mathrm{H}), 6.80-6.84(\mathrm{~m}, 8 \mathrm{H}), 6.96(\mathrm{~d}, J=3.7 \mathrm{~Hz}, 2 \mathrm{H}), 6.99-7.03$ $(\mathrm{m}, 8 \mathrm{H}), 7.26(\mathrm{dd}, J=7.3,1.1 \mathrm{~Hz}, 4 \mathrm{H}), 7.33-7.39(\mathrm{~m}, 8 \mathrm{H}), 7.45(\mathrm{dt}, J=$ $7.3,1.1 \mathrm{~Hz}, 4 \mathrm{H}), 7.60(\mathrm{~s}, 2 \mathrm{H}), 7.67(\mathrm{~d}, J=8.1 \mathrm{~Hz}, 4 \mathrm{H}), 7.85(\mathrm{~d}, J=8.5 \mathrm{~Hz}$ $4 \mathrm{H}), 7.88(\mathrm{~d}, J=3.7 \mathrm{~Hz}, 2 \mathrm{H}), 7.92 \mathrm{ppm}(\mathrm{d}, J=8.1 \mathrm{~Hz}, 4 \mathrm{H}) ;{ }^{13} \mathrm{C}$ NMR $\left(100 \mathrm{MHz}, \mathrm{CDCl}_{3}, 25^{\circ} \mathrm{C}\right): \delta=31.4,34.1,11.3,113.2,121.8,124.3,124.4$ 125.2, 125.7, 126.0, 126.2, 126.3, 127.0, 128.3, 128.4, 131.2, 135.2, 135.4, $138.3,143.2,144.7,145.1,145.7,149.5,152.4 \mathrm{ppm}$; FABMS: $\mathrm{m} / \mathrm{z} 1545.6$ $[M+\mathrm{H}]^{+}$; elemental analysis calcd (\%) for $\mathrm{C}_{106} \mathrm{H}_{92} \mathrm{~N}_{6} \mathrm{~S}_{3}$ : C 82.34, H 6.00, N 5.44; found: C 81.84, H 5.81, N 5.37.

5,5'-[5-(Thiophen-2-yl)-1,3-phenylene]bis[2-(3,5-di-tert-butylphenyl)thiophene] (3a): 3a was prepared by following a procedure similar to that described above for $\mathbf{G}_{\mathbf{1 a}}$ with the exception that 2-(3,5-dibromophenyl)thiophene was used instead of 4,7-dibromobenzothiadiazole. Colorless solid. Yield: $82 \% .{ }^{1} \mathrm{H}$ NMR $\left(300 \mathrm{MHz}, \mathrm{CDCl}_{3}, 25^{\circ} \mathrm{C}\right): \delta=1.38(\mathrm{~s}, 36 \mathrm{H})$, $7.12(\mathrm{dd}, J=3.8,3.8 \mathrm{~Hz}, 1 \mathrm{H}), 7.30(\mathrm{~d}, J=3.8 \mathrm{~Hz}, 2 \mathrm{H}), 7.33(\mathrm{~d}, J=3.8 \mathrm{~Hz}$ $1 \mathrm{H}), 7.38-7.41(\mathrm{~m}, 4 \mathrm{H}), 7.44(\mathrm{~d}, J=3.8 \mathrm{~Hz}, 1 \mathrm{H}), 7.48(\mathrm{~d}, J=1.8 \mathrm{~Hz}, 4 \mathrm{H})$, $7.75(\mathrm{~d}, J=1.8 \mathrm{~Hz}, 2 \mathrm{H}), 7.79 \mathrm{ppm}(\mathrm{t}, J=1.8 \mathrm{~Hz}, 1 \mathrm{H}) ;{ }^{13} \mathrm{C} \mathrm{NMR}(75 \mathrm{MHz}$, $\left.\mathrm{CDCl}_{3}, 25^{\circ} \mathrm{C}\right): \delta=31.5,34.9,120.4,121.9,122.1,122.3,123.8,123.9,124.6$ 125.3, 128.1, 133.5, 135.8, 142.2, 143.6, 145.6, $151.5 \mathrm{ppm}$; FABMS: $\mathrm{m} / \mathrm{z}$ $700.1[M]^{+}$; elemental analysis calcd $(\%)$ for $\mathrm{C}_{46} \mathrm{H}_{52} \mathrm{~S}_{3}$ : C 78.80, H 7.48; found: C 78.59, H 7.25 .

5-\{5-[3-(5-\{3,5-Bis [N-(4-tert-butylphenyl)- $N$-(naphthalen-1-yl)amino]phenyl\}thiophen-2-yl)-5-(thiophen-2-yl)phenyl] thiophen-2-yl]\}- $N^{1}, N^{3}$-bis(4tert-butylphenyl)- $N^{1}, N^{3}$-bis(naphthalen-1-yl)benzene-1,3-diamine (3b) 3b was prepared by following a procedure similar to that described above for $\mathbf{G}_{\mathbf{1 b}}$ with the exception that 2-(3,5-dibromophenyl)thiophene was used instead of 4,7-dibromobenzothiadiazole. Pale yellow solid. Yield: $79 \% .{ }^{1} \mathrm{H}$ NMR $\left(300 \mathrm{MHz}, \mathrm{CDCl}_{3}, 25^{\circ} \mathrm{C}\right): \delta=1.24(\mathrm{~s}, 36 \mathrm{H}), 6.45(\mathrm{t}$, $J=2.1 \mathrm{~Hz}, 2 \mathrm{H}), 6.71(\mathrm{~d}, J=2.1 \mathrm{~Hz}, 2 \mathrm{H}), 6.80-6.83(\mathrm{~m}, 8 \mathrm{H}), 6.88(\mathrm{~d}, J=$ $3.7 \mathrm{~Hz}, 2 \mathrm{H}), 6.99-7.07(\mathrm{~m}, 9 \mathrm{H}), 7.12(\mathrm{~d}, J=3.7 \mathrm{~Hz}, 2 \mathrm{H}), 7.25-7.30(\mathrm{~m}$, $6 \mathrm{H}), 7.33-7.40(\mathrm{~m}, 8 \mathrm{H}), 7.43-7.53(\mathrm{~m}, 7 \mathrm{H}), 7.67(\mathrm{~d}, J=8.1 \mathrm{~Hz}, 4 \mathrm{H}), 7.85$ $(\mathrm{d}, J=8.5 \mathrm{~Hz}, 4 \mathrm{H}), 7.92 \mathrm{ppm}(\mathrm{d}, J=8.1 \mathrm{~Hz}, 4 \mathrm{H}) ;{ }^{13} \mathrm{C} \mathrm{NMR}(75 \mathrm{MHz}$ $\left.\mathrm{CDCl}_{3}, 25^{\circ} \mathrm{C}\right): \delta=31.4,34.1,111.2,113.1,121.8,122.3,123.8,124.1,124.3$, $124.4,125.3,125.7,126.0,126.2,127.0,128.0,128.3,131.2,135.2,135.4$ 135.5, 142.2, 143.2, 143.4, 144.6, 144.7, 145.1, $149.5 \mathrm{ppm}$; FABMS: $\mathrm{m} / \mathrm{z}$ $1569.8[M+\mathrm{H}]^{+}$; elemental analysis calcd $(\%)$ for $\mathrm{C}_{110} \mathrm{H}_{96} \mathrm{~N}_{4} \mathrm{~S}_{3}$ : C 84.14, $\mathrm{H}$ 6.16, N 3.57; found: C 83.79, H 6.07, N 3.50 . 


\section{4,7-Bis(5-\{3,5-bis[5-(3,5-di-tert-butylphenyl)thiophen-2-yl]phenyl\}thio-} phen-2-yl)benzo[ $c][1,2,5]$ thiadiazole $\left(\mathbf{G}_{2 \mathrm{a}}\right)$ : $\mathbf{G}_{2 \mathrm{a}}$ was obtained as red solid in $74 \%$ yield from $\mathbf{3 a}$ and 4,7-dibromobenzothiadiazole as described for $\mathbf{G}_{1 \mathrm{a}} \cdot{ }^{1} \mathrm{H} \mathrm{NMR}\left(400 \mathrm{MHz}, \mathrm{CDCl}_{3}, 25^{\circ} \mathrm{C}\right): \delta=1.39(\mathrm{~s}, 72 \mathrm{H}), 7.32(\mathrm{~d}, J=$ $3.8 \mathrm{~Hz}, 4 \mathrm{H}), 7.40(\mathrm{t}, J=1.8 \mathrm{~Hz}, 4 \mathrm{H}), 7.42(\mathrm{~d}, J=3.8 \mathrm{~Hz}, 4 \mathrm{H}), 7.51(\mathrm{~d}, J=$ $1.8 \mathrm{~Hz}, 8 \mathrm{H}), 7.54(\mathrm{~d}, J=3.8 \mathrm{~Hz}, 2 \mathrm{H}), 7.80(\mathrm{t}, J=1.8 \mathrm{~Hz}, 2 \mathrm{H}), 7.82(\mathrm{~d}, J=$ $1.8 \mathrm{~Hz}, 4 \mathrm{H}), 7.92(\mathrm{~s}, 2 \mathrm{H}), 8.14 \mathrm{ppm}(\mathrm{d}, J=3.8 \mathrm{~Hz}, 2 \mathrm{H}) ;{ }^{13} \mathrm{C} \mathrm{NMR}$ $\left(100 \mathrm{MHz}, \mathrm{CDCl}_{3}, 25^{\circ} \mathrm{C}\right): \delta=31.5,34.9,120.3,121.7,121.9,122.1,123.8$, $124.7,125.2,125.5,128.5,133.5,135.3,135.7,139.1,142.1,144.5,145.5$, 151.4, $152.4 \mathrm{ppm}$; FABMS: $\mathrm{m} / \mathrm{z} 1533.9[\mathrm{M}]^{+}$; elemental analysis calcd (\%) for $\mathrm{C}_{98} \mathrm{H}_{104} \mathrm{~N}_{2} \mathrm{~S}_{7}$ : C 76.71, H 6.83, N 1.83; found: C 76.56, H 6.80, N 1.76 .

5-(5-\{3-[5-(4-\{5-[3,5-Bis(5-\{3,5-bis[ $N$-(4-tert-butylphenyl)- $N$-(naphthalen1-yl)amino]phenyl)thiophen-2-yl)phenyl]thiophen-2-yl\}benzo[c]$[1,2,5]$ thiadiazol-7-yl)thiophen-2-yl]-5-(5-\{3,5-bis $[N$-(4-tert-butylphenyl)$N$-(naphthalen-1-yl)amino] phenyl\}thiophen-2-yl)phenyl\}thiophen-2-yl)$N^{1}, N^{3}$-bis(4-tert-butylphenyl)- $N^{1}, N^{3}$-bis(naphthalen-1-yl)benzene-1,3-diamine $\left(\mathbf{G}_{\mathbf{2 b}}\right)$ : $\mathbf{G}_{\mathbf{2}}$ was obtained in $75 \%$ yield as described above for $\mathbf{G}_{\mathbf{1 b}}$ from $\mathbf{3 b}$ and 4,7-dibromobenzothiadiazole. Red solid. ${ }^{1} \mathrm{H}$ NMR $\left(400 \mathrm{MHz}, \mathrm{CDCl}_{3}, 25^{\circ} \mathrm{C}\right): \delta=1.23(\mathrm{~s}, 72 \mathrm{H}), 6.45(\mathrm{t}, J=2.1 \mathrm{~Hz}, 4 \mathrm{H}), 6.73$ $(\mathrm{d}, J=2.1 \mathrm{~Hz}, 8 \mathrm{H}), 6.81-6.84(\mathrm{~m}, 16 \mathrm{H}), 6.89(\mathrm{~d}, J=3.7 \mathrm{~Hz}, 4 \mathrm{H}), 7.00$ $7.04(\mathrm{~m}, 16 \mathrm{H}), 7.15(\mathrm{~d}, J=3.7 \mathrm{~Hz}, 4 \mathrm{H}), 7.26(\mathrm{dd}, J=7.3,1.1 \mathrm{~Hz}, 8 \mathrm{H})$, $7.33-7.52(\mathrm{~m}, 28 \mathrm{H}), 7.62-7.68(\mathrm{~m}, 12 \mathrm{H}), 7.83-7.87(\mathrm{~m}, 10 \mathrm{H}), 7.92(\mathrm{~d}, J=$ $8.5 \mathrm{~Hz}, 8 \mathrm{H}), 8.09 \mathrm{ppm}(\mathrm{d}, J=3.7 \mathrm{~Hz}, 2 \mathrm{H}) ;{ }^{13} \mathrm{C} \mathrm{NMR}\left(100 \mathrm{MHz}, \mathrm{CDCl}_{3}\right.$, $\left.25^{\circ} \mathrm{C}\right): \delta=31.5,34.2,11.4,113.3,122.0,122.2,124.3,124.6,125.5,125.8$, $126.1,126.3,126.4,127.1,128.5,128.7,131.3,135.4,135.6,135.7,139.3$, 142.3, 143.4, 144.8, 145.3, 149.7, 152.7 ppm; MALDI MS: $3273.7[M+\mathrm{H}]^{+}$; elemental analysis calcd (\%) for $\mathrm{C}_{226} \mathrm{H}_{192} \mathrm{~N}_{10} \mathrm{~S}_{7}$ : C 82.95, H 5.91; N 4.28; found: C 82.79, H 5.87, N 4.23.

$5,5^{\prime}, 5^{\prime \prime}, 5^{\prime \prime \prime}-\left(5,5^{\prime}-\left\{5,5^{\prime}-[5-(T h i o p h e n-2-y l)-1,3-p h e n y l e n e] b i s(t h i o p h e n e-5,2-\right.\right.$ diyl)\}bis(benzene-5,3,1-triyl))tetrakis[2-(3,5-di-tert-butylphenyl)thiophene] (4a): Pale yellow solid, prepared in 79\% yield from 3a and 2(3,5-dibromophenyl)thiophene as described above for 3a. ${ }^{1} \mathrm{H}$ NMR $\left(400 \mathrm{MHz}, \mathrm{CDCl}_{3}, 25^{\circ} \mathrm{C}\right): \delta=1.38(\mathrm{~s}, 72 \mathrm{H}), 7.15(\mathrm{dd}, J=3.8,3.8 \mathrm{~Hz}, 1 \mathrm{H})$, $7.32(\mathrm{~d}, J=3.8 \mathrm{~Hz}, 4 \mathrm{H}), 7.36(\mathrm{~d}, J=3.8 \mathrm{~Hz}, 1 \mathrm{H}), 7.39(\mathrm{t}, J=1.8 \mathrm{~Hz}, 4 \mathrm{H})$, $7.44(\mathrm{~d}, J=3.8 \mathrm{~Hz}, 4 \mathrm{H}), 7.46-7.50(\mathrm{~m}, 13 \mathrm{H}), 7.81(\mathrm{~s}, 8 \mathrm{H}), 7.85 \mathrm{ppm}(\mathrm{s}$, $1 \mathrm{H}) ;{ }^{13} \mathrm{C} \mathrm{NMR}\left(100 \mathrm{MHz}, \mathrm{CDCl}_{3}, 25^{\circ} \mathrm{C}\right): \delta=31.5,35.0,120.4,121.9$, $122.2,122.6,123.8,124.0,124.7,124.9,125.5,128.1,133.5,135.5,135.6$ 135.9, 142.1, 143.2, 143.5, 145.7, $151.5 \mathrm{ppm}$; FAB MS: $\mathrm{m} / \mathrm{z} 1558.0[\mathrm{M}]^{+}$; elemental analysis calcd (\%) for $\mathrm{C}_{102} \mathrm{H}_{108} \mathrm{~S}_{7}$ : C 78.61, H 6.99; found: $\mathrm{C}$ $78.54, \mathrm{H}, 6.82$.

4,7-Bis\{5-[3,5-bis(5-\{3,5-bis[5-(3,5-di-tert-butylphenyl)thiophen-2-yl]phenyl\}thiophen-2-yl)phenyl]thiophen-2-yl\}benzo[ $[c][1,2,5]$ thiadiazole $\left(G_{3 a}\right)$ : Prepared from 4a and 4,7-dibromobenzothiadiazole as described above for $\mathbf{G}_{\mathbf{1}}$. Red solid. Yield: $69 \%$. ${ }^{1} \mathrm{H}$ NMR $\left(400 \mathrm{MHz}, \mathrm{CDCl}_{3}, 25^{\circ} \mathrm{C}\right): \delta=$ $1.39(\mathrm{~s}, 144 \mathrm{H}), 7.30(\mathrm{~d}, J=3.8 \mathrm{~Hz}, 8 \mathrm{H}), 7.41(\mathrm{t}, J=1.8 \mathrm{~Hz}, 8 \mathrm{H}), 7.41$ (d, $J=3.8 \mathrm{~Hz}, 8 \mathrm{H}), 7.48(\mathrm{~d}, J=1.8 \mathrm{~Hz}, 16 \mathrm{H}), 7.55(\mathrm{~d}, J=3.8 \mathrm{~Hz}, 4 \mathrm{H}), 7.80(\mathrm{t}$, $J=1.8 \mathrm{~Hz}, 4 \mathrm{H}), 7.82(\mathrm{~d}, J=1.8 \mathrm{~Hz}, 8 \mathrm{H}), 7.89(\mathrm{~s}, 2 \mathrm{H}), 7.91(\mathrm{~s}, 4 \mathrm{H})$, $8.14 \mathrm{ppm}(\mathrm{d}, J=3.8 \mathrm{~Hz}, 4 \mathrm{H}) ;{ }^{13} \mathrm{C} \mathrm{NMR}\left(100 \mathrm{MHz}, \mathrm{CDCl}_{3}, 25^{\circ} \mathrm{C}\right): \delta=$ $31.4,34.8,120.3,121.7,121.8,122.0,123.8,124.1,124.7,125.0,125.3$, $125.6,128.0,128.5,133.5,135.4,135.6,136.0,139.1,142.2,143.1,143.6$, 144.5, 145.6, 151.4, 152.4 ppm; MALDI MS: $\mathrm{m} / \mathrm{z} 3247.1[\mathrm{M}]^{+}$; elemental analysis calcd (\%) for $\mathrm{C}_{210} \mathrm{H}_{216} \mathrm{~N}_{2} \mathrm{~S}_{15}$ : C 77.63, H 6.70, N 0.86; found: C $77.45, \mathrm{H} 6.56, \mathrm{~N} 0.81$.

5-(5-\{3-[5-(3-\{5-[3,5-Bis (5-\{3,5-bis[ $N$-(4-tert-butylphenyl)- $N$-(naphthalen1-yl)amino]phenyl\}thiophen-2-yl)phenyl]thiophen-2-yl\}-5-(thiophen-2-yl)phenyl)thiophen-2-yl]-5-(5-\{3,5-bis[ $N$-(4-tert-butylphenyl)- $N$-(naphthalen1-yl)amino]phenyl\}thiophen-2-yl)phenyl)thiophen-2-yl)- $N^{1}, N^{3}$-bis(4-tertbutylphenyl)- $\boldsymbol{N}^{1}, \boldsymbol{N}^{3}$-bis(naphthalen-1-yl)benzene-1,3-diamine (4b): Compound $\mathbf{4 b}$ was obtained in $86 \%$ yield as described above for $\mathbf{3 b}$ from $\mathbf{3 b}$ and 2-(3,5-dibromophenyl)thiophene. Pale yellow solid. ${ }^{1} \mathrm{H}$ NMR $\left(400 \mathrm{MHz}, \mathrm{CDCl}_{3}, 25^{\circ} \mathrm{C}\right): \delta=1.22(\mathrm{~s}, 72 \mathrm{H}), 6.72(\mathrm{~d}, J=2.1 \mathrm{~Hz}, 8 \mathrm{H})$, $6.80-6.83(\mathrm{~m}, 16 \mathrm{H}), 6.88(\mathrm{~d}, J=3.7 \mathrm{~Hz}, 4 \mathrm{H}), 6.99-7.02(\mathrm{~m}, 16 \mathrm{H}), 7.13$ $7.15(\mathrm{~m}, 5 \mathrm{H}), 7.27(\mathrm{~d}, J=7.2 \mathrm{~Hz}, 8 \mathrm{H}), 7.32-7.39(\mathrm{~m}, 21 \mathrm{H}), 7.42-7.51(\mathrm{~m}$, $11 \mathrm{H}), 7.57(\mathrm{~d}, J=1.5 \mathrm{~Hz}, 4 \mathrm{H}), 7.66(\mathrm{~d}, J=8.5 \mathrm{~Hz}, 8 \mathrm{H}), 7.74(\mathrm{~s}, 3 \mathrm{H}), 7.84$ $(\mathrm{d}, J=8.1 \mathrm{~Hz}, 8 \mathrm{H}), 7.92 \mathrm{ppm}(\mathrm{d}, J=8.5 \mathrm{~Hz}, 8 \mathrm{H}) ;{ }^{13} \mathrm{C} \mathrm{NMR}(100 \mathrm{MHz}$, $\left.\mathrm{CDCl}_{3}, 25^{\circ} \mathrm{C}\right): \delta=31.4,34.1,111.2,113.1,121.8,122.4,124.1,124.4,124.8$, $125.7,126.0,126.2,127.0,128.3,131.2,135.2,135.4,135.6,142.1,143.2$,
144.7, 145.1, $149.6 \mathrm{ppm}$; MALDI MS: $m / z 3297.6[M+\mathrm{H}]^{+}$; elemental analysis calcd (\%) for $\mathrm{C}_{230} \mathrm{H}_{196} \mathrm{~N}_{8} \mathrm{~S}_{7}$ : C 83.80, H 5.99, N 3.40; found: C 83.67, H 5.98, N 3.46

Dendrimer $\mathbf{G}_{\mathbf{3 b}}$ was obtained in $75 \%$ yield as described above for $\mathbf{G}_{\mathbf{1 b}}$ from $\mathbf{4 b}$ and 4,7-dibromobenzothiadiazole. Red solid. ${ }^{1} \mathrm{H}$ NMR $\left(400 \mathrm{MHz}, \mathrm{CDCl}_{3}, 25^{\circ} \mathrm{C}\right): \delta=1.21(\mathrm{~s}, 144 \mathrm{H}), 6.46(\mathrm{~s}, 8 \mathrm{H}), 6.54(\mathrm{~s}, 2 \mathrm{H})$, $6.71(\mathrm{~d}, J=2.1 \mathrm{~Hz}, 16 \mathrm{H}), 6.79-6.88(\mathrm{~m}, 40 \mathrm{H}), 6.98-7.02(\mathrm{~m}, 32 \mathrm{H}) 7.13(\mathrm{t}$ $J=2.1 \mathrm{~Hz}, 6 \mathrm{H}), 7.26(\mathrm{~d}, J=7.3 \mathrm{~Hz}, 12 \mathrm{H}), 7.32-7.46(\mathrm{~m}, 62 \mathrm{H}), 7.51-7.58$ $(\mathrm{m}, 10 \mathrm{H}), 7.65(\mathrm{~d}, J=8.1 \mathrm{~Hz}, 18 \mathrm{H}), 7.79-7.84(\mathrm{~m}, 22 \mathrm{H}), 7.89-7.96(\mathrm{~m}$, $18 \mathrm{H}), 8.18 \mathrm{ppm}(\mathrm{s}, 2 \mathrm{H}) ;{ }^{13} \mathrm{C}$ NMR $\left(100 \mathrm{MHz}, \mathrm{CDCl}_{3}, 25^{\circ} \mathrm{C}\right): \delta=31.4$, $34.1,111.3,111.7,113.2,121.8,124.2,124.4,125.7,126.0,126.2,127.0$, $128.3,131.2,135.2,143.2,144.7,145.1,149.6 \mathrm{ppm}$; MALDI MS: $\mathrm{m} / \mathrm{z}$ $6726.5[M+\mathrm{H}]^{+}$; elemental analysis calcd (\%) for $\mathrm{C}_{466} \mathrm{H}_{392} \mathrm{~N}_{18} \mathrm{~S}_{15}$ : C 83.22, H 5.88, N 3.75; found: C 82.98, H 5.91, N 3.62 .

\section{Acknowledgement}

We thank Academia Sinica, National Taiwan University, and National Science Council for financial support.

[1] a) P. L. Burn, S.-C. Lo, I. D. W. Samuel, Adv. Mater. 2007, 19, $1675-$ 1688; b) S.-C. Lo, P. L. Burn, Chem. Rev. 2007, 107, 1097-1116; c) V. Balzani, P. Ceroni, M. Maestri, C. Saudan, V. Vicinelli, Top. Curr Chem. 2003, 228, 159-191; d) A. Adronov, J. M. J. Fréchet, Chem. Commun. 2000, 1701-1710; e) J. S. Moore, Acc. Chem. Res. 1997, $30,402-413$

[2] S. Hecht, J. M. J. Fréchet, J. M. Angew. Chem. 2001, 113, 76-94; Angew. Chem. Int. Ed. 2001, 40, 74-91; Angew. Chem. Int. Ed. 2001 40, 74-91.

[3] a) M. S. Choi, T. Yamazaki, I. Yamazaki, T. F. Aida, Angew. Chem. 2004, 116, 152-160; Angew. Chem. Int. Ed. 2004, 43, 150-158; b) F. Vögtle, S. Gestermann, R. Hesse, H. Schwierz, B. A. Windisch, Prog. Polym. Sci. 2000, 25, 987-1041.

[4] J. Q. Qu, J. Y. Zhang, A. C. Grimsdale, K. Müllen, F. Jaiser, Z. H Yang, D. Neher, Macromolecules 2004, 37, 8297-8306.

[5] K. R. J. Thomas, J. T. Lin, Y.-T. Tao, C.-H. Chuen, Adv. Mater. 2002, $14,822-826$.

[6] a) K. R. Justin Thomas, M. Velusamy, J. T. Lin, S.-S. Sun, Y.-T. Tao, C.-H. Chuen, Chem. Commun. 2004, 2328-2329; b) K. R. J. Thomas, M. Velusamy, J. T. Lin, Y.-T. Tao, C. H. Chuen, Adv. Funct. Mater. 2004, 14, 83-90; c) C.-H. Chen, J. T. Lin, M.-C. P. Yeh, Org. Lett. 2006, 8, 2233-2236.

[7] a) C. Flors, I. Oesterling, T. Schnitzler, E. Fron, G. Schweitzer, M Sliva, A. Herrmann, M. van der Auweraer, F. C. De Schryver, K Müllen, J. Kofhens, J. Phys. Chem. C 2007, 111, 4861-4870; b) S. M. Melnikov, E. K. L. Yeow, H. Uji-i, M. Cotlet, K. Müllen, F. C. De Schryver, J. Enderlein, J. Hofkens, J. Phys. Chem. B 2007, 111, 708719 ; c) R. Augulis, A. Pugžlys, J. H. Hurenkamp, B. L. Feringa, J. H. van Esch, P. H. M. van Loosdrecht, J. Phys. Chem. A 2007, 111 12944-12953; d) I. Oesterling, K. Müllen, J. Am. Chem. Soc. 2007 129, 4595-4605.

[8] a) G. Ramakrishna, A. Bhaskar, P. Bauerle, T. Goodson III, J. Phys. Chem. A 2008, 112, 2018-2026; b) Y. Zhang, C. Zhao, J. Yang, M Kapiamba, O. Haze, L. J. Rothberg, M.-K. Ng, J. Org. Chem. 2006 71, 9475-9483; c) C. Q. Ma, E. Mena-Osteritz, T. Debaerdemaeker, M. M. Wienk, R. A. J. Janssen, P. Bäuerle, Angew. Chem. 2007, 119, 1709-1713; Angew. Chem. Int. Ed. 2007, 46, 1679-1683; d) Y. Zhang, Z. Wang, M.-K. Ng, L. J. Rothberg, J. Phys. Chem. B 2007, 111, 13211-13216; e) J. L. Wang, J. Luo, L. H. Liu, Q. F. Zhou, Y. Ma, J. Pei, Org. Lett. 2006, 8, 2281-2284; f) W. J. Mitchell, N. Kopidakis, G. Rumbles, D. S. Ginley, S. E. Shaheen, J. Mater. Chem. 2005 15, 4518-4528; g) C. J. Xia, X. W. Fan, J. Locklin, R. C. Advincula, A. Gies, W. Nonidez, J. Am. Chem. Soc. 2004, 126, 8735-8743; h) C Xia, X. Fan, J. Locklin, R. C. Advincula, Org. Lett. 2002, 4, $2067-$ 2070 . 
[9] a) J. Q. Qu, N. G. Pschirer, D. J. Liu, A. Stefan, F. C. De Schryver, K. Müllen, Chem. Eur. J. 2004, 10, 528-537; b) D. J. Liu, S. De Feyter, M. Cotlet, A. Stefan, U. M. Wiesler, A. Herrmann, D. GrebelKoehler, J. Q. Qu, K. Müllen, F. C. De Schryver, Macromolecules 2003, 36, 5918-5925.

[10] a) K. R. Justin Thomas, J. T. Lin, Y.-T. Tao, C.-W. Ko, Chem. Mater. 2002, 14, 1354-1361; b) Y. Z. Su, J. T. Lin, Y.-T. Tao, C.-W. Ko, S. C. Lin, S.-S. Sun, Chem. Mater. 2002, 14, 1884-1890.

[11] Principles of Fluorescence Spectroscopy, 2nd ed. (Ed.: J. R. Lakowicz), Plenum Publishing, New York, 1999.

[12] G. T. Hwang, B. H. Kim, Org. Lett. 2004, 6, 2669-2672.

[13] a) H. E. Zimmermann, J. Am. Chem. Soc. 1995, 117, 8988-8991; b) M. I. Ranasinghe, M. W. Hager, C. B. Gorman, T. Goodson, J. Phys. Chem. B 2004, 108, 8543-8549; c) K. M. Gaab, A. L. Thompson, J. J. Xu, T. J. Martinez, C. J. Bardeen, J. Am. Chem. Soc. 2003, 125, 9288-9289; d) E. Opsitnick, E. Lee, Chem. Eur. J. 2007, 13, $7040-7049$.
[14] a) J. M. Serin, D. W. Brousmiche, J. M. J. Fréchet, Chem. Commun 2002, 2605-2607; b) S. L. Gilat, A. Adronov, J. M. J. Fréchet, Angew. Chem. 1999, 111, 1519-1524; Angew. Chem. Int. Ed. 1999 38, 1422-1427; c) C. Devadoss, P. Bharathi, J. S. Moore, J. Am Chem. Soc. 1996, 118, 9635-9644.

[15] a) K. R. Justin Thomas, A. L. Thompson, A. V. Sivakumar, C. J. Bardeen, S. Thayumanavan, J. Am. Chem. Soc. 2005, 127, 373-383; b) T. S. Ahn, A. Nantalaksakul, R. R. Dasari, R. O. Al-Kaysi, A. M. Müller, S. Thayumanavan, C. J. Bardeen, J. Phys. Chem. B 2006, 110, 24331-24339; c) K. W. Pollak, E. M. Sanford, J. M. J. Frèchet, $J$ Mater. Chem. 1998, 8, 519-527.

[16] Y. Shirota, J. Mater. Chem. 2005, 15, 75-93.

[17] a) C. B. Gorman, C. R. Chim. 2003, 6, 911-918; b) C. M. Cardona, S. Mendoza, A. E. Kaifer, Chem. Soc. Rev. 2000, 29, 37-423.

Received: August 14, 2008 Revised: September 26, 2008 Published online: November 7, 2008 